\title{
Street involved drug use, social dynamics and interactions with police in Ottawa
}

\author{
by \\ Steven Hardy
}

A thesis submitted to the Faculty of Graduate and Postdoctoral Affairs in partial fulfillment of the requirements for the degree of

Master of Legal Studies

in

M.A. Legal Studies

Carleton University

Ottawa, Ontario

(C) 2017, Steven Hardy 


\begin{abstract}
Homeless populations are frequently associated with drug consumption. Drug use by homeless people is more visible leading to the assumption that homeless or street involved populations use drugs more frequently or differently than other segments of the population. In this paper, I challenge this idea and consider how homeless and street involved populations consume drugs and how they understand their drug consumption. In 15 semi-structured, openended interviews I explored how homeless and street involved men consume drugs and how they view their drug use. Their drug use is within the broader societal context that impacts their understandings and views of drug consumption. Using Peta Malins' definition of the "junkie", I explore the impact of this idea on how drugs are consumed by homeless and street involved populations. Drawing on the idea of subjectivities, this paper looks at how these individuals understand what it means to be a "junkie" and how they understand their own drug consumption in response. Police have an impact on the daily lives of street involved drug users. This paper explores how police interact with street involved drug users and how street involved drug users understand these interactions. Finally, I consider how the "junkie" subjectivity impacts interactions between street involved users and police.
\end{abstract}




\section{$\underline{\text { Acknowledgements }}$}

The completion of this project was possible because 15 street involved men graciously allowed me a glimpse into their lives. The staff of the shelter where I met these men went above and beyond their duty to help me every step of the research. My family supported me throughout this entire project in too many ways to name. Dr. Dale Spenser, my Supervisor, offered constructive counsel, timely insights and encouragement throughout the multi-year process. I appreciate the work of second reader, Dr. Nicolas Carrier, external reader Dr. Neil Gerlach and the Defense Committee, Drs. Spenser, Carrier, Gerlach, chaired by Dr. Ron Saunders. They offered valuable comments, suggested changes and met on short notice. Without everyone named, and someone I'm sure I've missed, this project would not have been completed. 


\section{$\underline{\text { Table of Content }}$}

Table of Contents

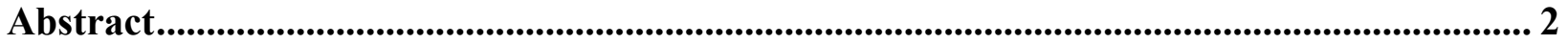

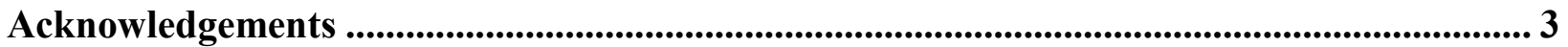

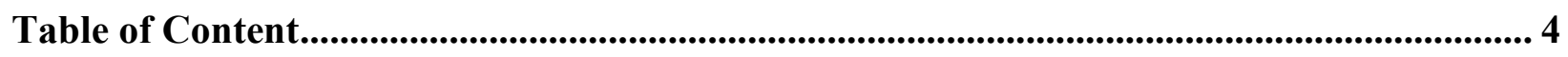

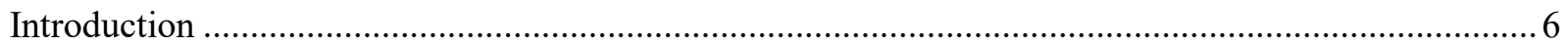

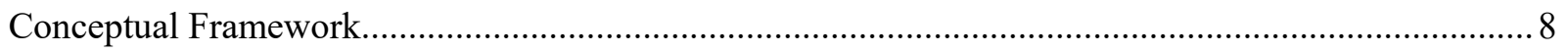

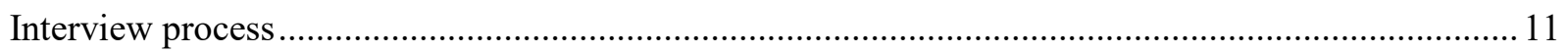

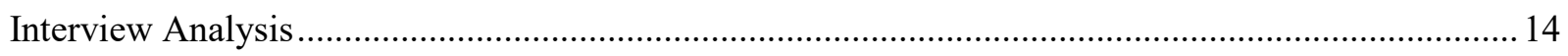

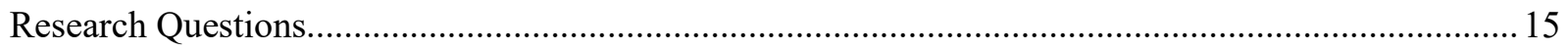

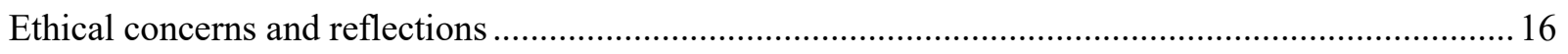

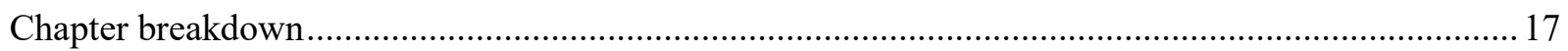

Chapter 1 History of Canada's Drug Policy ......................................................................................... 19

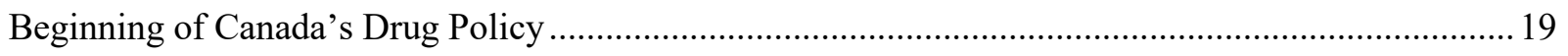

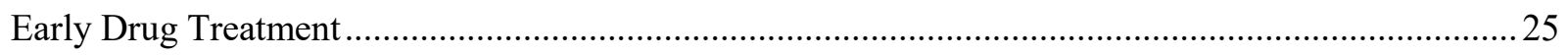

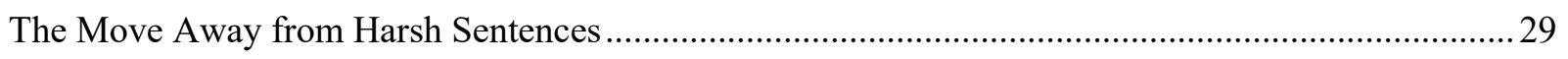

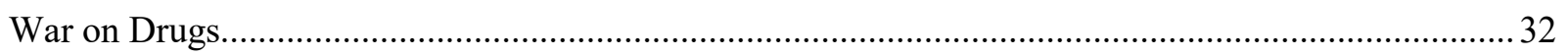

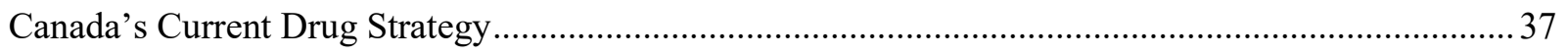

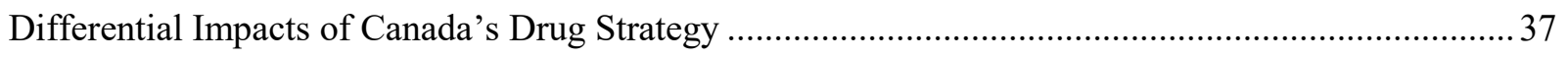

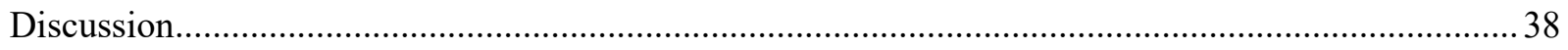

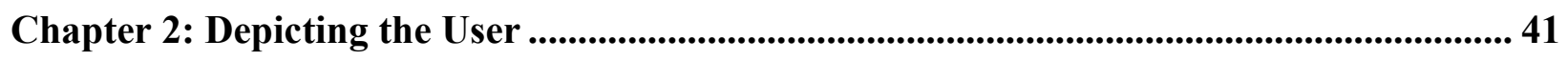

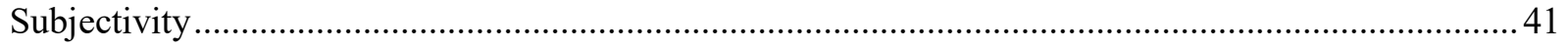

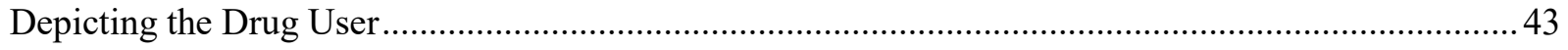

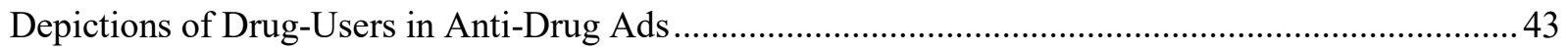

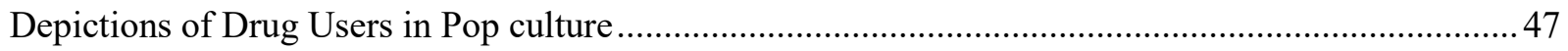




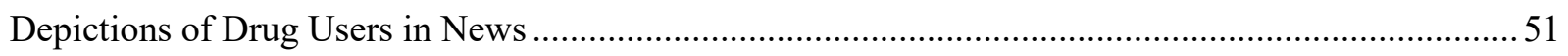

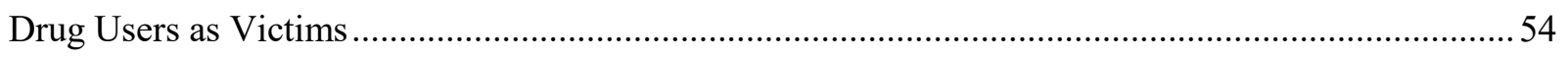

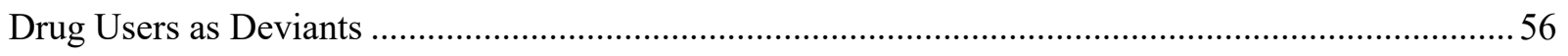

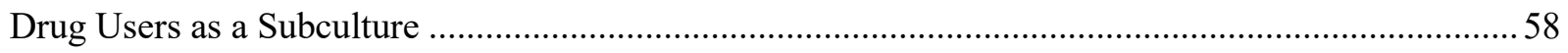

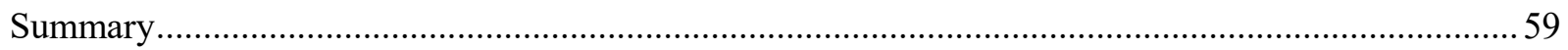

Chapter 3: Relationships and Subjectivities Among Street Involved Users ........................... 61

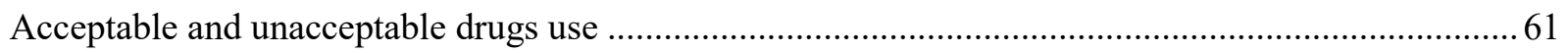

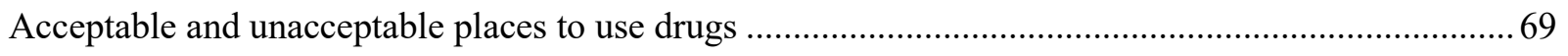

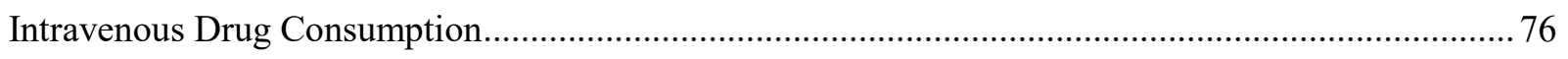

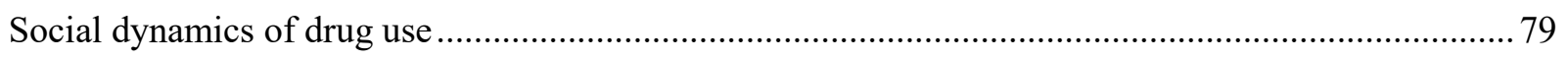

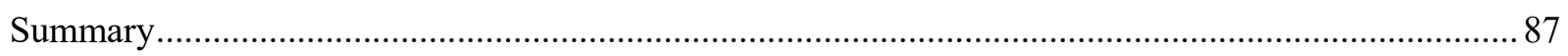

Chapter 4: Interactions with Police.................................................................................... 89

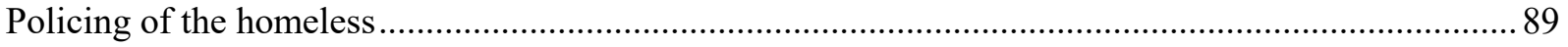

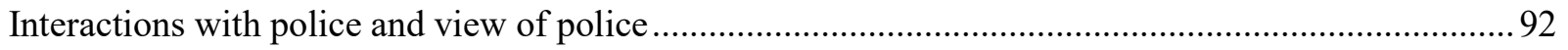

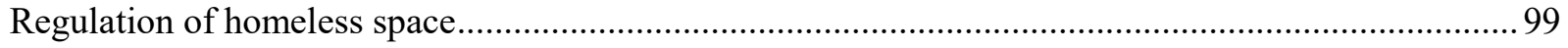

Routinization of avoiding police and group strategies of avoiding police when using drugs ............. 103

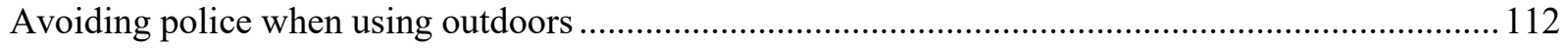

Consistent themes with police and street involved drug users .................................................... 121

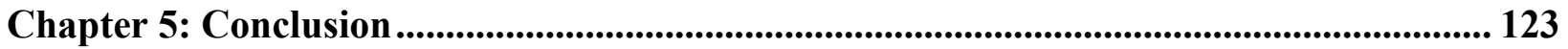

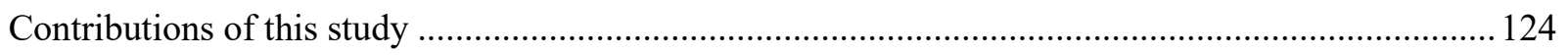

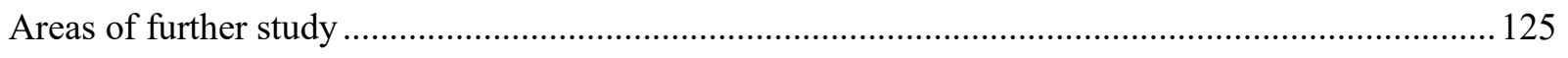

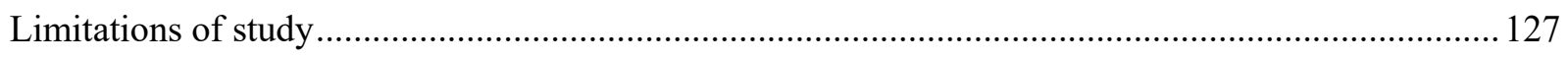

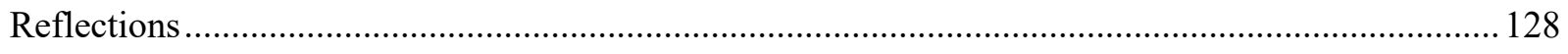

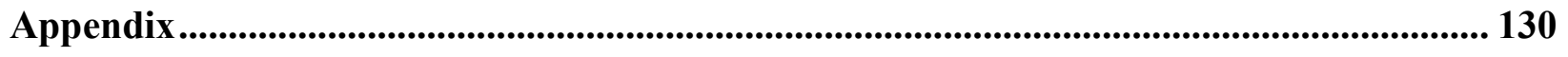

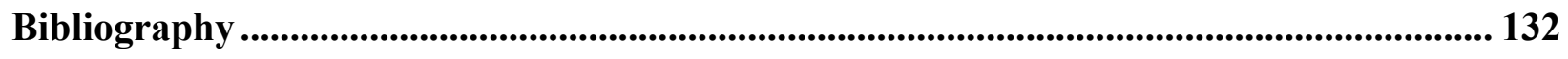




\section{Introduction}

Labels such as "bum", "degenerate", "drunk", "crack head", and "junkie" are frequently used when people describe homeless and street involved populations. These populations are frequently associated with the consumption of drugs and alcohol. The consumption of drugs and alcohol may contribute to why individuals end up homeless or street involved.

The notion that homeless or street involved populations use drugs more frequently than other populations is common, so much so that one estimate from the United Kingdom claimed $50-70 \%$ of the United Kingdom's homeless population were using illicit drugs. ${ }^{1}$ In Robert M. Bray and Mary Ellen Marsden's book Drug Use in Metropolitan America, they wrote that homeless populations often demonstrated "high rates of drug use, alcohol use, needle use, and symptoms of dependence...".2 A 1992 paper by Anne Shlay and Peter Rossi claimed: "alcohol and drug abuse characterize a significant proportion of the population of homeless persons". ${ }^{3}$ The linking of homeless and drug consumption has become so ingrained that in 2009 the National Coalition for the Homeless considered drug use to be one of the leading causes of homelessness in America. ${ }^{4}$ Those who are street involved or homeless consume drugs within the

\footnotetext{
${ }^{1}$ Nat Wright, Drug Users With Special Needs Drug Use and Homelessness in "Care of Drug Users in General Practice: A Harm Reduction Approach”, (United Kingdom: Radcliffe Publishing, 2004). At page 99

${ }^{2}$ Robert M. Bray, Mary Ellen Marsden, Drug Use in Metropolitan America, (Thousand Oaks, California: SAGE, 1999). At page 118.

${ }^{3}$ Anne B. Shlay and Peter H. Rossi, "Social Science Research and Contemporary Studies of Homelessness", Annual Review of Sociology 18, 1992. At page 139

4 “Substance Abuse and Homelessness", National Coalition for the Homeless, July 2009
} 
dominant social context that has been imposed upon them and in which their drug consumption is inherently problematic or different than the drug consumption of more affluent populations.

The law is intended to apply equally to everyone, however rarely does it impact populations in the same way. Poor or racialized communities may be policed differently and be more likely to encounter the law. A recent study of law enforcement in San Francisco found that poor and racialized communities were far more likely to encounter law enforcement particularly when it came to drug related offences. ${ }^{5}$ The study further found that poorer areas of San Francisco were policed more intensely than other areas, especially as it pertained to drug related offences. ${ }^{6}$. A Washington-based study that examined policing in three neighbourhoods similarly found that racialized poor populations are treated differently by police. ${ }^{7}$ Racialized and marginalized groups in Canada may also face differential treatment from police, and at various other points from the criminal justice system. ${ }^{8}$ They may be more likely to encounter police on a regular basis regardless of whether they are more likely to commit an offence.

I challenge the belief that homelessness and drug consumption are inseparably linked and examine if homeless and street involved populations consume drugs differently or at a higher rate than other populations. This paper will call into question the assumption that street involved or homeless populations can be defined by their drug consumption and examine the commonly held belief that street involved or homeless populations are solely motivated by their desire to

\footnotetext{
${ }^{5}$ Lynch et al. "Policing the 'progressive' city: The racialized geography of drug law enforcement" Theoretical Criminology 17:3 2013. At page 345.

${ }^{6}$ Ibid at page 349

${ }^{7}$ Ronald Weitzer, "Racialized policing: Residents' perceptions in three neighborhoods", Law \& Society Review 31:1 2000. At page 151

${ }^{8}$ Grace-Edward Galabuz, Canada's Economic Apartheid: The Social Exclusion of Racialized Groups in the New Century, (Toronto, ON: Canadian Scholars' Press, 2006). At page 199.
} 
consume drugs. It will demonstrate that street involved drug users make rational and logical decisions regarding their drug use and are not defined by and solely motivated by their desire to consume drugs. Through interviews with 15 street involved men in Ottawa I will examine how they navigate the conceptions of street involved drug consumption imposed on them by dominant discourse. To do so. I will draw on Peta Malins' definition of the "junkie" and demonstrate how street involved drug users must navigate this stigmatized subjectivity. Avoiding this subjective position is a guiding force for what street involved drug users define as acceptable and unacceptable consumption.

\section{Conceptual Framework}

I employ the term 'street involved' when referencing those individuals regularly involved in life on the streets with precarious housing situations. By using this term, I include individuals who may or may not have access to housing and spend a substantial amount of time on the streets involved with street activities. Like the term street involved youth, "street involved" tries to capture individuals who spend significant amounts of time on the street. ${ }^{9}$ I particularly avoid the term homeless as these individuals may not necessarily be homeless and may not identify as being homeless. They may have insufficient housing and may be heavily involved in street activity without being homeless. ${ }^{10}$ They may also have a variety of precarious housing situations that may result in them spending time on the streets without being homeless or self-identifying as homeless. It is likely that some of the street involved individuals will not own or rent a private residence and may rely on community shelters, or a network of peer support for housing. While

\footnotetext{
${ }^{9}$ Brandon D.L. Marshall et al., "Homelessness and unstable housing associated with an increased risk of HIV and STI transmission among street-involved youth", Health \& Place 15:3 2009. At page 784

${ }^{10}$ Darlene Clover, "Successes and challenges of feminist arts-based participatory methodologies with homeless/street-involved women in Victoria", Qualitative Social Work 9:1 2015. At page 25
} 
this may allow me to classify them as homeless, I do not want to confuse them with those who are sleeping outdoors on a regular basis. As such I avoid the term homeless as I feel it may focus too much on varying housing situations and not enough on the commonalities of street involvement which is the primary focus. Further, this research is enhanced because participants define themselves rather than applying an externally determined definition or label they may feel is appropriate.

Drawing on Gleghorn et al.'s definition of street youth, the term 'street involved' can also include those: "involved in the illegal street economies of drugs, prostitution, theft, or panhandling". ${ }^{11}$ In using the term "street involved", I may be neglecting a group of drug users who are not involved in street activity and I may be attaching an identity to my participants with which they do not identify. Street involved, as used by Gleghorn et al., suggests that individuals who are street involved are also engaged in criminal activity. This may not always be the case. While street involved drug users are involved in illegal drug use, they may not be involved with prostitution, theft or panhandling.

My goal in using the term "street involved" is to have broad enough terminology to encompass the range of individuals who may be involved with this research and not to apply a label or create a subjectivity for research participants. I specifically avoided using the term homeless for this reason as some participants may have access to housing and may not consider themselves homeless.

I also use the term 'drug user' not drug addict or drug dependant. While some users suffer from addiction and drug dependency, this does not apply to all. To define someone as an

\footnotetext{
${ }^{11}$ Alice A. Gleghorn et al., "Association between drug use patterns and HIV risks among homeless, runaway, and street youth in Northern California", Drug and Alcohol Dependence 51:3 1998. At page at page 219.
} 
addict would be applying a subjectivity to research participants that they themselves may reject. While I do not deny that some users may struggle with addiction, it is not up to me to define their subjectivity and how they identify themselves. For an outsider to define someone as being an addict would require in-depth knowledge of tolerance, sensitization, dependence and withdrawal from a medical standpoint. ${ }^{12}$ My intention is not to deny that these conditions exist, but rather to avoid engaging in medical definitions about which I am ignorant. This study is designed to understand drug user's daily realities and how police influence this reality.

Subjectivity will be a major focus of this research project. I will examine how street involved drug users view themselves and how external factors influence their view of themselves. Essentially, how street involved drug users constitute themselves. I will examine how certain subjectivities are created and imposed on street involved drug users and how they navigate these subjectivities. This will involve testing how externally applied labels such as "junkie" become internalized and impact behaviour. ${ }^{13}$

I use the notion of hard and soft drugs that is part of the dominant discourse on drugs. Drugs such as marijuana are considered soft whereas drugs such as heroin or cocaine are hard. This is not to suggest that I agree or disagree with these classifications, however these socially created distinctions were reinforced during interviews and are reflected in this paper.

This study is specifically focussed on consumption of illegal drugs and does not examine alcohol use. I chose to narrow the focus of this thesis to consider only illegal drugs because examining alcohol from a socio-legal perspective would require specific study and a separate

\footnotetext{
${ }^{12}$ Eric J. Nestler et al., "Drug addiction: A model for the molecular basis of neural plasticity", Neuron 11:6 1993. At page 995

${ }^{13}$ Kelly G. Shaver, "Principles of Social Psychology: Third Edition”, (New York, NY: Psychology Press, 2015) at page 253 .
} 
research project. My chosen project would not have allowed enough scope to examine the unique legal history of alcohol or to compare it with other legal and illegal drugs.

My study focuses on how the law and society help to create the image of the street involved drug user. It examines how the law impacts street involved people consuming drugs, how drug use is viewed in society and the impact this has on them.

\section{Interview process}

I designed and administered open-ended semi-structured interviews that were conducted at a downtown Ottawa shelter over two days. Each interview lasted between 10-30 minutes depending on the interviewee. Respondents were provided with a \$10 Tim Horton's gift card for their participation.

I chose this shelter for two main reasons. The first being that it had a more lenient attitude towards drug consumption, and second out of convenience. When I first became interested in pursuing this research project I had a contact working as a nurse in the shelter who offered to be

of assistance. She sent me the contact information of the person who could be of more assistance and informed them I would be in contact. The shelter was enthusiastic about my project, found the topic interesting and relevant. They recommended I volunteer prior to conducting interviews to gain better insight into the shelter and as a curtesy. Following a one year wait for ethics approval I began interviewing. The shelter staff was extremely helpful and provided a private room in which to conduct the interviews. They informed clients I was there and of the $\$ 10$ gift card available. Some respondents also informed other respondents of the study. I did not directly recruit any participants.

Staff also informed me that they often had researchers coming into the shelter as the population I was trying to reach was frequently studied. The frequent studying of this population 
may have been one reason why staff were extremely knowledgeable and supportive. This may also have helped me gain access. Conversely, conducting research and interviews with a frequently studied population may lead to respondent fatigue and make it more difficult to gain trust. ${ }^{14}$ My impression from respondents was that my time volunteering helped earn the trust of some clients, and that many clients had not participated in other research projects. However, I did not question respondents on their previous participation in research projects. Over-studied populations who are used to participating in interviews may also be used to providing certain answers to researchers. This may lead to less candid and honest responses that don't provide useful data. While I may never know how honest respondents were, based on the depth of information they provided and openness during the interviews, I felt they were candid and honest.

Homeless or street involved populations are considered a hard to reach group. Members of hard to reach groups may be reluctant to self identify as such because of social stigma attached to being a member of a certain group. ${ }^{15}$ In order to reach these groups it is necessary to physically go to where they are to access their social group. ${ }^{16}$ A truly random sample from a hard to reach group is generally not obtainable, rather a convenience sample that refers other members is the only alternative. ${ }^{17}$ Street involved and homeless populations do not necessarily have a

\footnotetext{
${ }^{14}$ Alan Bryman, Social Research Methods, (Oxford, UK: Oxford University Press, 2015). At page 139.

15 Tyler H. McCormick et al., "Surveying Hard-to-Reach Groups Through Sampled Respondents in a Social Network A Comparison of Two Survey Strategies", Statistics in Bioscience 4:1 2012. At page 178

${ }^{16}$ Ibid at page 178

${ }^{17}$ Leo A. Goodman, "COMMENT: ON RESPONDENT-DRIVEN SAMPLING AND SNOWBALL SAMPLING IN HARD-TO-REACH POPULATIONS AND SNOWBALL SAMPLING NOT IN HARD-TO-REACH POPULATIONS", Sociological Methodology 41:1 2011. At page 350
} 
regular daily schedule or consistent access to email meaning that scheduling interviews can be difficult, coming to them and making it easier for them is an easy solution. ${ }^{18}$

Open ended semi-structured interviews were determined to be the best method of data collection for the goals of this study. Interviewees narrated their experiences in their own words, thus allowing members of a traditionally disfavoured group to speak on their own terms. The quotes used have not been altered or edited and the language they used is the exact language that appears in this paper. This open approach was most appropriate to challenge the hegemonic discourse. The production of a narrative involves a subject position that may be tied to a particular identity. ${ }^{19}$ This enables us to better understand the realities faced by disfavoured groups such as, in this instance, street involved drug users. Using narratives gave voice to those who have traditionally been denied a voice, and allowed me to bring into question some of the traditional assumptions about these individuals. ${ }^{20}$ To allow individuals to narrate their own experiences, responses of interviewees were not limited. The aim of this study is to understand street involved drug users on their own terms therefore it was essential to allow them to express themselves as possible within the confines of an interview.

This study utilized qualitative rather than quantitative data collection. The nature of this study does not lend itself to greatly generalizable results because the sample selection is restricted to one city with a small sample size. However, qualitative research allowed more indepth study for a greater understanding of the narratives and experiences of street involved drug

\footnotetext{
${ }^{18}$ Joshua D. Phillips, Homeless: Narratives from the Streets, (North Carolina: McFarland, 2015). At page 81

${ }^{19}$ Mario Barnes, "Black women's stories and the criminal law: restating the power of narrative", U.C. Davis law review 39:3 2006. At page 952.

${ }^{20}$ Ibid at page 954
} 
users. This greater depth of research allowed me to understand more about how these individuals conceptualize themselves, and how they view their own drug consumption.

\section{Interview Analysis}

After transcribing the interviews, data was sorted and categorized. The data was coded based on research questions. I was left with multiple files of data and transcripts with each one speaking to a slightly different theme. These included, but where not limited to, where respondents consumed, how they consumed, who they consumed with, why they consumed with certain people, how they viewed police and their view of police. Coding the data can make it easier to identify consistent themes in the data to be understood and analyzed. ${ }^{21}$ I found this to be the case and once data was coded major themes and patterns become clear.

Analyzing qualitative data requires researchers to make interpretations and inferences regarding their data. ${ }^{22}$ When analyzing and interpreting my data I was primarily concerned with respondents' narrative and understanding. A narrative allows individuals to organize their knowledge and experience and make sense of and understand their world. ${ }^{23}$ Narratives can be an opening into the mind of individuals and when analyzing narratives from a group of people they can present a window into their culture. ${ }^{24}$ I was not concerned if respondents' narratives were a

\footnotetext{
${ }^{21}$ Graham R Gibbs, “Analysing Qualitative Data”, (Thousand Oak, CA: SAGE, 2008). At page 2

${ }^{22}$ Ibid at page 2

${ }^{23}$ Martin Cortazzi, "Narrative Analysis”, (Abingdon, Oxon: Routledge, 2014). At page 1

${ }^{24} \mathrm{Ibid}$ at page 2
} 
direct reflection of reality. I was interested in how they perceived and made sense of their realities and that is how I approached the interviews and subsequently analyzed them.

\section{Research Questions}

This study examined how street involved drug users perceive their consumption and how the socially constructed notion of the "junkie" has impacted their drug consumption habits. "Junkie" is an externally applied label and the study examined how street involved users understood and internalized the "junkie" and how this impacts their drug consumption. This required me to consider how the "junkie" label is internalized and the implications it carries.

To do this, the research questions explored how and why users differentiated acceptable and unacceptable drug consumption. Questions probed why needles were used and why some choose to be alone versus in a group when consuming. Questions such as: "who do you use drugs with" proved useful to understand these issues. Responses to these questions increased understanding of how the idea of being a "junkie" impacted their decisions and tested the impact of this external label on internal decision making. I questioned if users changed or defined their consumption habits to avoid a label and subjectivity as well as if they regulated their existence accordingly. Asking respondents "are there any drugs you won't use and why not", aided me in understanding why they may avoid certain drugs. If their consumption habits were determined by the avoidance of a label or subjective position, it would suggest that drug consumption was a part of their lives that is interwoven into a complex reality of street involved life. And it suggested that drug consumption was not the defining feature of their lives and that their decisions about drugs were like other populations notwithstanding that the street involved population faces increased stigmatization about drug consumption or the idea of being a "junkie". 
The stigmatization of being a "junkie" and the association between street involved people and "junkie" impacts how they are policed. This study examined how street involved populations understood, internalized and navigated the dominant discourse on street involved drug consumption as well as how these external labels impacted how they chose and consumed drugs. As well, research questions probed how these external factors affected interactions with police and how users understood their relationship with police. Questions such as "how do the police treat you" and "are there certain areas in the city the police treat you differently" were aimed at gaining a better understanding of their interpretation of their relationship with police.

\section{Ethical concerns and reflections}

Potential ethical implications with this type of qualitative research project were recognized and considered. Respondents were asked to discuss illegal drug consumption and potentially reveal incriminating information about themselves or their peers. This meant that maintaining the anonymity of interviewees was of the utmost importance. The shelter itself had a lenient policy towards drug consumption and participation in my study would not impact how they were treated or the services they received at the shelter. Before conducting the research, I worked, and continue to work, as a volunteer once a week running bingo for an hour. This allowed me to gain a better appreciation for the culture of the shelter and become a familiar and hopefully trusted face around the shelter.

I endeavoured not to present myself as an authority figure. I tried to make a clear distinction between the staff and me to ensure clients of the shelter and respondents were aware that I held no official power at the shelter. Regardless of my best attempts I am also aware that whenever a researcher enters an environment their presence alone may alter that environment 
and how individuals perceive that environment. ${ }^{25}$ While I tried to avoid appearing as an authority figure I can never be certain how I was perceived. My perception was that interviewees were aware that I had no official power or authority, however some may have perceived that I had unofficial power or influence. I will never know the extent to which this was the case and this may have influenced how some interviewees responded to certain questions and their level of candidness.

\section{Chapter breakdown}

This study challenges the notion that homeless or street involved populations use drugs differently or more frequently than other populations. Specifically, this study tested the extent to which these populations consume drugs and how the dominant discourse about street level drug use impacts perceptions. To do this, in the following chapters, I show how Canadian drug policy criminalizes certain drugs and how street involved drug users have been marginalized and socially ostracized as a result. Using the narratives and interviews I explore how street involved drug users understand their drug consumption and how they avoid the potential legal consequences of illegal drug consumption.

The first chapter will explain the history of Canada's drug policy with a focus on illegal drugs to show the historical legal context of current drug policy. This illustrates how the law views the consumption of certain drugs as problematic, and those who consume these drugs as criminals or deviants.

\footnotetext{
${ }^{25}$ Mats Alvesson and Kaj Sköldberg, "Reflexive Methodology: New Vistas for Qualitative Research", (Thousand Oaks, California: SAGE, 2009). At page 8.
} 
The second chapter explores subjectivity, specifically how drug consumption and drug users are viewed by society. I will show how socio-economically marginalized groups that consume drugs are viewed differently than more affluent consumers. The "junkie" is an artificially created social category and this chapter will explore how these social constructions are created.

The third chapter examines how street involved people who consume drugs navigate the "junkie" subjectivity. The "junkie" is a heavily stigmatized identity that only applies to street involved individuals who must navigate the legal realities of their drug use differently than more affluent populations. The association between being a "junkie" and a street level drug user impacts how users regulate and understand their own drug consumption. Avoiding the "junkie" subjectivity is often paramount to how street involved people decide on acceptable and unacceptable drug consumption. In some instances, it may dictate their drug consumption patterns, including where and with whom they will consume.

The final chapter looks at the interactions between street involved drug users and the police. The stigmatization of street involved people consuming drugs may influence the policing approach and the resulting interactions with police. Police may treat them differently due to the association between street involvement and what police may view as problematic drug consumptions, or more succinctly, police officers may apply the label of "junkie". To close this chapter, how street involved people interact with and avoid police will be considered. 


\section{Chapter 1 History of Canada's Drug Policy}

In this chapter, the legal history of Canada's drug policy is examined to understand how Canada has responded to drugs and drug users from earliest drug laws to current approaches. By examining Canada's historic response to drugs, the legal realities that have faced drug users and those interacting with drug users on a regular basis, becomes obvious. Those who interact with street involved users include those who provide medical and harm reduction services. This outlines how the law responds to drugs, drug users and those attempting to provide care to street involved drug users. It will also provide background for the current legal context faced by drug users. This chapter will focus on the beginnings of Canada's drug policy, Canada's early attempts at drug treatment, the move away from harsher sentences, the war on drugs and conclude by examining Canada's current drug policy. This will establish how the law views certain drugs as problematic and how it responds to this perceived problem. Canada's drug policy has often criminalized both the drug and those who consume it. In doing so, Canada's drug policy has furthered the idea that the consumption of certain drugs is inherently criminal or deviant. Because these laws were aimed at certain populations and not others, these laws helped create artificial images of drug users. This furthered the idea that certain populations use drugs more frequently and that their use is more problematic than other populations.

\section{Beginning of Canada's Drug Policy}

Prior to 1908 all drugs were legal in Canada, including cocaine, marijuana, opium, and alcohol. The 1908 Opium Act, targeted opium, and was Canada's first piece of legislation aimed at controlling drug use. It prosecuted people for importation, manufacture, or sale of crude or powdered opium or of opium prepared for smoking. ${ }^{26}$ In 1911 the crime of possession was

\footnotetext{
${ }^{26}$ Statutes of Canada 1908, c. 50
} 
added. Before 1908 drugs such as opium, heroin and cocaine were freely used in Canada and even prescribed by physicians. In 1907, 44 tons of opium were imported into Canada, largely for legal and socially accepted medical practices. ${ }^{27}$ Cocaine and opium were used for a wide range of health problems from diarrhea to pain, while heroin was used to relieve coughs. ${ }^{28}$ Syrups containing opium were even given to infants to help them sleep. ${ }^{29}$ The majority of users where white upper class Canadians. ${ }^{30}$ The records of the Niagara Apothecary from 1853-1875 show that the majority of customers purchasing narcotics were from the skilled working class or social elites. ${ }^{31}$ This group included masons, shoemakers, carpenters, army officers and even politicians. The records of the Niagara Apothecary may not be indicative of drug use across the country but they do indicate the general attitude towards drug use. Understanding drug use among those without access to narcotics either because of financial or geographic reasons is more difficult. In Dan Malleck's When Good Drugs Go Bad: Opium, Medicine, and the Origins of Canada's Drug Laws, he asserts that by examining home remedies, self-help books, and compilations of folk remedies, evidence suggests that poorer Canadians often used opium as a small part of home remedies for health problems. ${ }^{32}$ Malleck does not suggest however that poor and working-class Canadians used drugs to the same extent as the skilled working class and social elite. Rick Csiernik and Robin Koop-Watson contend in Responding to the Oppression of Addiction:

\footnotetext{
${ }^{27}$ James W. St.G. Walker, "“Race," Rights and the Law in the Supreme Court of Canada: Historical Case Studies", (Canada: The Osgoode Society for Canadian Legal History and Wilfred Laurier University Press, 1997), at page 84

${ }^{28}$ Edgar-André Montigny, "The Real Dope: Social, Legal, and Historical Perspectives on the Regulation of Drugs in Canada", (Toronto: University of Toronto Press, 2011). At page 7.

${ }^{29}$ Walker supra note 2 at page 83

${ }^{30}$ Ibid at page 7.

${ }^{31}$ Dan Malleck, "When Good Drugs Go Bad: Opium, Medicine, and the Origins of Canada's Drug Laws", (Vancouver: UBC Press, 2015) at page 18

${ }^{32}$ Ibid at page 19 .
} 
Canadian Social Work Perspectives that during the late 1800s and early 1900s drug use was: "an indulgence of the upper class, and to a lesser extent the Canadian middle class". ${ }^{33}$ They further suggest that opium addicts were viewed as "individuals with specific moral transgressions" who were either pitied or despised depending on their ethnicity. ${ }^{34}$

Despite the use of opium by many upper class white Canadians its use was not considered a major issue in Canada until opium became associated with Asian immigrants who were originally brought to Canada to work on the Canadian Pacific Railway. Once Asian migrant labour was no longer needed, opium became an issue. Following the completion of the Canadian railway, Asian immigrants who were brought over to build the railway, often chose to stay in Canada. Due to the Chinese head tax, which rose from fifty dollars to five hundred dollars between 1885 and 1903, many were unable to bring their families over with them. ${ }^{35}$ They then began to establish themselves and their businesses in Canada. These businesses were in competition with Euro-Canadian owned businesses and in 1907 the anti-Asian riots in Vancouver damaged many Asian owned businesses. Following the riots, then Deputy Minister of Labour, William Lyon Mackenzie King, was assigned to assess damage done to Asian business and consider what compensation they should receive from the Federal Government. It was while on this inspection that he noticed the substantial opium industry in British Columbia. ${ }^{36}$ At this point opium was not illegal. While there was a substantial percentage of Asian users there were

\footnotetext{
${ }^{33}$ Rick Csiernik and Robin Koop-Watson, "Many Paths to Prohibition: Drug Policy in Canada", in Responding to the Oppression of Addiction: Canadian Social Work Perspectives, (Toronto: Canadian Scholars Press, 2010), at page 315 .

${ }^{34}$ Ibid at page 315

${ }^{35}$ K.W. Taylor, "Racism in Canadian immigration policy,” Canadian Ethnic Studies 23:1 (1991). At paragraph 18.

${ }^{36}$ John McLaren, Race and the Criminal Justice System in British Columbia, 1892-1920, in Essays in the History of Canadian Law: In honour of R.C.B. Risk ed. (Toronto: University of Toronto Press, 1999). At page 406.
} 
also many Euro-Canadian users. The laws enacted focused on punishing opium dealers, most of which were Chinese. ${ }^{37}$

One of the major concerns about opium use was its effect on Euro-Canadians and not just Asian immigrants. When Euro-Canadian women were found in opium dens, moral panic set in as people worried about how they would keep women safe from the evils of Chinese opium dens. This had more to do with the concern about white Canadian women with Chinese men in opium dens than with the actual harm caused by opium. Foreign immigrants were perceived to pose a threat to Canadian standards as their culture was foreign to that of Euro-Canadians. ${ }^{38}$ The use of opium was not the primary concern but rather the concern was non-conformity of the Asian population as well as extremely negative racial attitudes towards Asian immigrants.

In 1909 the Criminal Code was amended to give police extra powers to enforce the 1908 Opium Act. ${ }^{39}$ The panic surrounding drugs would eventually move beyond opium and in 1911 drug prohibition was increased to cover the entire opiate and cocaine families. ${ }^{40}$ The addition of cocaine was once again due to moral panic and not reasoned scientific evidence. Especially in Montreal, there was concern that cocaine use would soon become rampant and legal changes were needed to protect the children. ${ }^{41}$

Emily Murphy was the first person to bring the idea of marijuana prohibition to peoples' attention in Canada. In the 1920's she published a series of articles that called for stricter drug

\footnotetext{
${ }^{37}$ Opium Act 1908 - Chapter 12 Available online at $<$ http://www.parl.gc.ca/Content/SEN/Committee/371/ille/rep/repfinalvol2-e.htm\#>

${ }^{38}$ P.J Giffen et al. Panick and Indifference: The Politics of Canada's Drug Laws, Ch 2 - Social Origins of Narcotic Prohibition (1991). At page 47.

${ }^{39}$ Ibid at page 77

${ }^{40} \mathrm{Ibid}$ at page 78

${ }^{41}$ Ibid at page 84
} 
prohibitions in Canada and warned of the dangerous effects of drug use. While there are realistic risks and dangers associated with drug use, Murphy's anti-drug activism was based more on racial attitudes than the actual risks associated with drug use. Murphy said that drugs were part of a conspiracy to "injure the bright borrowed races of the world". ${ }^{42}$ She claimed that drug use was a tactic used by: "aliens of colour to bring about the degeneration of the white race" ${ }^{43}$ Despite the racial overtones of her work Murphy was a Judge at the time of the articles and her anti-drug activism was taken seriously. Marijuana prohibition is perhaps the best example of her arguments being accepted despite lacking scientific evidence. Her article Marahuana-A New Menace was published in 1922, and in 1923 marijuana was added to list the illegal drugs in Canada. In the article Murphy quotes Los Angeles Police Chief Charles A. Jones, who claimed that those using marijuana become "completely insane" and "lose all sense of moral responsibility". ${ }^{44}$ The Officer went so far as to claim "if this drug is indulged to any great extent, it ends in the untimely death of its addict". ${ }^{45}$ Murphy concluded by stating that there were only three possible ways out from the addictive force of marijuana: insanity, death and abandonment. ${ }^{46}$ None of Murphy's claims were substantiated, however, in 1923 marijuana was added to the list of the illegal substances.

Moral reformers also played a role in the creation of early Canadian drug policy. Some moral reformers perceived opiates as a menace that would continue to destroy Christian morals

\footnotetext{
${ }^{42}$ Linda A. Mooney et al. Understanding Social Problems. (Belmont, CA: Cengage Learning, 2010). At page 87.

${ }^{43}$ Ibid at page 87

${ }^{44}$ Emily Murphy, Black Candle, Part 2, Chapters 17-25. Available on Freeworldnews.com. $<\underline{\text { http://www.freeworldnews.com/p2_17to25.html\#Marahuana--A_New_Menace }>}$

${ }^{45}$ Ibid

${ }^{46}$ Ibid
} 
and inhibitions thereby exposing man's natural tendency towards depravity. ${ }^{47}$ Unlike the moral campaigns against alcohol and tobacco that had relatively little impact, the campaign against opiates was much more effective in influencing public opinion. The intersection between morality and race may have had an impact as opiates were commonly associated with Asian migrants.

From 1930-1950 the number of prohibited drugs as well as the range of drug offences was continuously increased. ${ }^{48}$ At the same time the Division of Narcotic Control, which was part of the Department of Health, dictated Canada's drug policy. Created in 1920, the Division of Narcotics Control consisted of federal drug prosecutors and their counterparts at the Royal Canadian Mounted Police. ${ }^{49}$ The Division was able to catalyze domestic pressures, external influences and its own interests into legislation which helped define Canadian drug policy. ${ }^{50}$ To justify its existence, the Division relied heavily on rigorous drug law enforcement. ${ }^{51}$ Drug penalties increased consistently from 1920-1960. Despite escalating penalties and increased police powers, the actual number of annual drug offence convictions peaked in the early $1920 \mathrm{~s}$ but then fell rapidly by the end of the decade. ${ }^{52}$ This decline may be partially attributable to the

\footnotetext{
${ }^{47}$ Robert R. Solomon and Melvyn Green, “The First Century: The History of Non-Medical Opiate Use and Control Policies in Canada 1870-1970", in Crime and Deviance in Canada: Historical Perspectives, (Toronto: Canadian Scholars' Press, 2005). At page 353

${ }^{48}$ Frederick John Desroches, The Crime that Pays: Drug Trafficking and Organized Crime in Canada, (Toronto: Canadian Scholars' Press, 2005). At page 16

${ }^{49}$ Patricia G. Erickson and David L Haans, "Drug War, Canadian Style”, in Drug War American Style: The Internationalization of Failed Policy and its Alternatives, (New York: Garland Publishing, 2001). At page 121

${ }^{50}$ Desroches supra note 22 at page 16

${ }^{51}$ Robert R. Solomon and Melvyn Green supra note 22 at page 357

${ }^{52}$ Ibid at page 358
} 
death of many older Chinese opium smokers who accounted for many convictions, as well as convicted opium smokers who were deported. ${ }^{53}$

Between 1930 and 1952 Canadian drug policy underwent three major changes. In 1938 the offence of cultivating opium and cannabis were added, deportation provisions were transferred to immigration policy and in 1952 the list of illegal narcotics was expanded to include compound and synthetic narcotics. ${ }^{54}$ By the beginning of the 1950 s there were questions about the criminalization approach to drugs and, although it remained the predominant approach to drugs and drug users, there was an effort to establish drug treatment as an alternative.

\section{Early Drug Treatment}

The original premise behind drug treatment as an alternative to criminalization was the view that drug addiction was a social and medical condition not a crime. Instead of viewing drug users as criminals or deviants, drug users were individuals in need of help. This is a different subjective position than criminal or deviant. Media reports from the United States regarding high rates of addiction especially among youth sparked coverage of similar issues in Canada. ${ }^{55}$ This created a growing concern for drug addicts and drug addiction in Canada. Despite the growing concern for drug addicts, the dominant discourse at the time continued to frame working class and poor users of illegal drugs as being criminal addicts. ${ }^{56}$ This was true in both Canada and the United States and both countries maintained harsh drug laws despite growing concern for the welfare of addicts. In Canada drug traffickers could still be sentenced to death and in the United

\footnotetext{
53 Ibid at page 358

${ }^{54}$ Ibid at page 358

55 Ibid at page 359

${ }^{56}$ Susan C. Boyd, Hooked: Drug War Films in Britain, Canada, and the United States, (Toronto: University of Toronto Press, 2009). At page 61.
} 
States those convicted of trafficking to minors could receive the death sentence. ${ }^{57}$ The drug treatment movement in Canada sought to change this perception of drug addicts, they viewed addicts as individuals in need of medical attention rather than criminals deserving of harsh sentences.

The drug treatment movement in Canada originated out of Vancouver in response to both media coverage of drug addiction as well as a city scare of teenage drug users. ${ }^{58}$ This led to the appointment of an independent committee to examine the city's illegal drug problem. The findings of this committee were released in 1952 as the Ranta Report. The Report made two recommendations regarding the city's drug problem, however both ran counter to Canada's policy on illegal drugs at the time. The first recommendation called for a pilot medical and treatment centre for illegal drug users, and the second advocated for provincial narcotic clinics which would allow registered narcotics users to receive maintenance doses of illegal drugs. ${ }^{59}$ Following the Ranta report, a permanent lobby for medical treatment of drug users was established. The Standing Committee on the Prevention of Narcotic Addiction (The Committee) was organized by the Community Chest and Council of Greater Vancouver. ${ }^{60}$ The Committee challenged the dominant view of drug addicts as criminals and proposed a more nuanced classification of drug users and drug traffickers. The Committee recommended that addicts possessing drugs for their own use should be treated as a medical not criminal problem. The addict who traffics only small amounts of drugs should only be subjected to minor criminal

\footnotetext{
${ }^{57}$ Ibid at page 61 .

${ }^{58}$ Kyle Grayson, Chasing Dragons: Security, Identity, and Illicit Drugs in Canada, (Toronto: University of Toronto Press 2008). At page 141

${ }^{59}$ Ibid at page 141

${ }^{60}$ Ibid at page 142
} 
punishment with room for sentencing discretion and only those who are not addicts but rather large-scale traffickers of drugs should be subject to serious criminal punishment. ${ }^{61}$ Both the Ranta Report and The Committee were able to challenge the dominant narrative surrounding drugs in Canada. Changes were noticeable such as a pilot project in 1954 for addiction treatment. It was the first of its kind in Canada, however, criminalization remained the dominant approach to illegal drug use. ${ }^{62}$

Despite these subtle changes in the discourse and attitudes about illegal drugs in Canada the Federal Government still favoured a policy of criminalization. Minister of Health Paul Martin Sr. supported treatment for addicts. He did not however, support the idea of maintenance dosages and still believed that drug users needed to be removed from the public through confinement. At a 1955 Special Senate Committee on the Traffic of Narcotic Drugs, Martin Sr. dismissed the view that drug users were themselves victims and instead stressed the criminal nature of illegal drug users which required harsh criminal justice measures. Martin Sr. went on to argue that drug treatment programs were the responsibility of the provinces and not the Federal Government to quash any further attempts to implement a medical based drug policy. ${ }^{63}$ While the medical movement was successful in challenging dominant views on illegal drugs and drug users in Canada, it was not able to fundamentally alter Canada's drug policy in the ways suggested in both the Ranta Report and by The Committee.

However, as part of the movement towards a more medically based drug policy in Canada, treatment options began to become more common. Methadone treatment remains one of

\footnotetext{
${ }^{61} \mathrm{Ibid}$ at page 142

${ }^{62} \mathrm{Ibid}$ at page 143

${ }^{63} \mathrm{Ibid}$ at page 143
} 
the most common treatments to opiate addiction. ${ }^{64}$ Methadone is a long acting synthetic opioid that acts to alleviate symptoms of opiate withdrawal. ${ }^{65}$ Methadone treatment has been available as a treatment option in Canada since 1961. Prior to 1961 Canadian drug laws prohibited the prescription of opioids to opiate users even for medical purposes. ${ }^{66}$ The Narcotics Control Act of 1961 allowed opiates to be used for medical treatment for opiate addicted individuals. This was following the 1959 trial of methadone for short term withdrawal symptoms by the Narcotic Addiction Research Foundation of British Columbia ${ }^{67}$ In 1963 the first methadone maintenance treatment program was opened in British Columbia by Dr. Robert Halliday. The program was aimed at older users with whom other drug treatment methods had proved largely unsuccessful. ${ }^{68}$ In 1964 the Addiction Research Foundation of Ontario adopted its own methadone maintenance program and by the late 1960s methadone maintenance programs were widely available across Canada. ${ }^{69}$

Methadone treatment fits within the medical approach to illegal drugs and drug users. The methadone treatment programs were based on the view that drug users are not inherently criminals but rather approached drug addiction as a medical issue. Methadone maintenance programs were a way of rehabilitating addicts to become productive members of society.

\footnotetext{
${ }^{64}$ The terminology of 'addict' is problematic. The notion of who is and is not an addict may be dependant on a variety of factors beyond drug consumption. While I do not accept this terminology in all instances it was the terminology used within early drug treatment.

65 “Best Practices Methadone Maintenance Treatment", Health Canada 2002. At page 6.

${ }^{66}$ J. E. Peachey and T. Franklin. "Methadone Treatment of Opiate Dependence in Canada", British Journal of Addiction 80:3 1985. At page 291

${ }^{67}$ Ibid at page 291

${ }^{68}$ Catherine Carstairs, Jailed for Possession: Illegal Drug Use, Regulation, and Power in Canada, 1920-1961, (Toronto: University of Toronto Press, 2006). At page 127

${ }^{69}$ Ibid at page 127
} 
Following the 1959 methadone trial in British Columbia, Dr. Halliday wrote that the: "treatment approach is instrumental in changing the hitherto hopeless lives of many addicts into more constructive ones". ${ }^{70}$ This approach to drug users was sharply different than the criminalization approach. The medical movement may have been successful in changing how some people viewed the consumption of illegal drugs however they continued to be criminalized.

\section{The Move Away from Harsh Sentences}

Throughout the 1960s, criticism of Canada's drug policy became louder and more mainstream. Concerns over drug issues were being raised and people began to question harsh criminal sentences for possession of small amounts of illegal drugs. In 1969, prosecutors were given the option of pursuing summary convictions in possession charges and the Narcotics Control Act was amended to include fine only sentencing options. ${ }^{71}$ In 1972 amendments to the Criminal Code allowed judges to impose an absolute or conditional discharge allowing for a guilty verdict without criminal conviction. Judges responded to these powers and to the changing attitudes around drugs by imposing less severe penalties. ${ }^{72}$ This was a significant change from earlier drug policy which favoured stronger sentencing for drug users.

In the early 1970s the Le Dain Commission began to look at the non-medical use of drugs. The Le Dain Commission issued four reports and recommended that Canada move towards a harm reduction approach to drugs and gradually withdraw criminal sanctions for drug

\footnotetext{
${ }^{70}$ Ingeborg Paulus and Robert Halliday, "Rehabilitation and the Narcotic Addict Results of a Comparative Methadone Withdrawal Program", Canadian Medical Association Journal 96:11 1967. At page 658 .

${ }^{71}$ Desroches supra note 22 at page 16

${ }^{72}$ Ibid at page 16
} 
use. ${ }^{73}$ While the recommendations of the Le Dain Commission were never enacted, it does demonstrate the changing attitudes and perception of drug users in Canada. One of the Le Dain Commission's findings was that media reports on drugs, especially early media reports, relied very heavily on police and law enforcement sources. The result being that media reports often amplified the actual harm surrounding drugs. ${ }^{74}$ This had a significant impact in shaping public opinion as well as the early discourse and rhetoric about drugs and drug users. ${ }^{75}$

Perhaps the most famous recommendation of the Le Dain Commission was the removal of marijuana from the Criminal Code. The Le Dain Commission recommended that marijuana be classified under the Food and Drug Act rather than the Criminal Code. ${ }^{76}$ While the decriminalization of marijuana was discussed following the recommendation of the Le Dain Commission, it did not lead to a significant policy change regarding marijuana decriminalization.

The Le Dain Commission looked at the impact of heroin and cocaine as well as marijuana. Like recommendations on marijuana, it recommended ending prison time for the possession of heroin and cocaine. ${ }^{77}$ While this would not decriminalize heroin and cocaine, it would have been a substantial shift in Canadian drug policy. It would also have signaled a shift to a more medically-based policy for drugs. Like the other recommendations of the Le Dain Commission, this was largely ignored and criminalization for the possession of heroin and cocaine remain part of Canada's drug policy.

\footnotetext{
${ }^{73}$ Ibid at page 16

${ }^{74}$ Susan C. Boyd, and Connie Carter, Killer Weed: Marijuana Grow Ops, Media, and Justice, (Toronto: University of Toronto Press, 2014). At page 52.

${ }^{75}$ Ibid at page 52

${ }^{76}$ Paula Mallea, The War on Drugs: A Failed Experiment, (Toronto: Dundurn, 2014). At page 175

${ }^{77}$ Susan C. Boyd, and Connie Carter supra note 48 at page 52
} 
Alcohol has never been a major component of Canadian drug policy outside of a brief period around World War I (WWI) when prohibition was implemented. The length of prohibition in Canada was determined by each province and alcohol continues to be a provincial rather than federal matter. However, outside of Prince Edward Island, it was relatively short lived and loopholes existed allowing people to still consume alcohol without criminal penalty. Despite not being a major part of Canadian drug policy, the Le Dain Commission identified alcohol as being harmful, perhaps even more so than many illegal drugs. ${ }^{78}$ The Le Dain Commission also noted that alcohol was North America's worst dependency problem, the high number of Canadians arrested annually for public drunkenness and that many Canadians did not even view alcohol as being a drug. ${ }^{79}$ Similar results were found in a more recent study done by Professor David Nutt, a former chief drugs adviser to the British government. Nutt ranked sixteen drugs based on the harms the drug caused to the user as well as harms to society and determined alcohol was the most harmful. ${ }^{80}$ Heroin, crack cocaine, and methamphetamine caused the most harm to drug users however alcohol was deemed the most harmful drug to society. ${ }^{81}$ While Nutt's study was done in the United Kingdom, his findings are applicable in North America. Despite the Le Dain Commission's findings, and similar findings of Nutt,

\footnotetext{
${ }^{78}$ Robert A Campbell, "Profit Was Just a Circumstance": The Evolution of Government Liquor Control in British Columbia 1920-1988" in Drink in Canada: Historical Essays, (Montreal: McGill-Queen's Press - MQUP, 1993) at page 188 .

${ }^{79}$ Greg Marquis "From Beverage to Drug: Alcohol and Other Drugs in 1960s and 1970s Canada" in The Real Dope: Social, Legal, and Historical Perspectives on the Regulation of Drugs in Canada, (Toronto: University of Toronto Press, 2011). At page 225

${ }^{80}$ David J Nutt et al., "Drug harms in the UK: a multicriteria decision analysis" (2010) 376 The Lancet 1558. at page 1561

${ }^{81} \mathrm{Ibid}$ at page 1561
} 
alcohol never became a major component of Canada's drug policy and remains absent today. Alcohol continues to fall under provincial jurisdiction.

The Le Dain Commission was released about the same time as the American War on Drugs began. Media coverage from the United States regarding drug use helped fuel a concern in Canada about domestic drug use which made a progressive drug policy more difficult to implement. The result being that Canada's drug policy remained focused on criminalization and law enforcement.

\section{War on Drugs}

The War on Drugs in Canada never escalated to the extremes of the American War on Drugs, at least domestically. However, the American War on Drugs did have an impact on Canadian domestic drug policy. This helped to re-establish the drug user as being a criminal and deviant and, because the war on drugs targeted certain populations and not others, it also helped to create ideas of who was a problematic or criminal drug user. Drug consumers who were racialized and socio-economically marginalized were impacted more severely. This furthered the idea that the consumption of illegal drugs was particular to populations that were already racialized and socio-economically marginalized. While these ideas were false, they created a perception of who was consuming drugs.

Unfortunately, Le Dain Commission's progressive recommendations were released at the same time President Richard Nixon announced the beginning of America's War on Drugs. Canadian politicians did not want to appear soft on drugs or risk the wrath of the United States and as a result the recommendations of the La Dain Commission were largely ignored. ${ }^{82}$ During

\footnotetext{
${ }^{82}$ Paula Mallea supra note 50 at page 175
} 
a Throne Speech in 1980 Prime Minister Pierre Trudeau publicly stated that possession of marijuana should not result in imprisonment, however Canadian justice officials increased enforcement efforts resulting in incarceration of even more drug offenders. This may be largely due to the tough on drugs mentality in the United States at the time. ${ }^{83}$ This meant that despite the suggestions of the La Dain Commission, Canada was returning to a tough on crime approach to drugs.

The American War on Drugs was started by Richard Nixon and resulted in a dramatic increase in incarcerations for drug related offences. Following the Vietnam War there was concern within the United States about an increase in heroin use, especially among returning soldiers. Nixon declared that drugs were "public enemy number one in the United States". Despite the tough on crime approach to drugs Nixon spent more money on drug treatment than on law enforcement. ${ }^{84}$ This would be the only time during the American War on Drugs when drug treatment would receive more funding that law enforcement. During the 1970s the United States began a significant effort both domestically and internationally as part of its War on Drugs.

By the 1980s one of the major concerns in the United States was the purported threat of crack cocaine. The de-industrialization of the United States in the 1970s and 80s, saw the loss of manufacturing jobs from the urban core of many American cities. This left many Americans facing the prospects of low wage, unskilled, and often humiliating employment or entering the

\footnotetext{
${ }^{83}$ Ibid at page 175

84 “Thirty Years of America's Drug War a Chronology”, Frontline. Available online < http://www.pbs.org/wgbh/pages/frontline/shows/drugs/cron/>
} 
underground economy. ${ }^{85}$ Within the urban United States the effects of de-industrialization were often felt the strongest. Selling crack cocaine became one way to avoid low wage and humiliating work. Selling crack was a predominantly low level and a relatively simple operation without any central organization or control that was undertaken by members of the predominantly poor, black inner-city population. ${ }^{86}$ The Anti-Drug Abuse Act of 1986 created the 100-1 sentencing disparity between crack and cocaine. Despite being essentially the same drug, five grams of crack would receive a five-year minimum sentence whereas 100 grams of cocaine to receive the same sentence. This targeted poor, predominantly black street level drug dealers. The result of this sentencing disparity was the imprisonment of a disproportionate number of black Americans. ${ }^{87}$ While the disparity was reduced to $18-1$ by the 2010 Fair Sentencing Act, crack is still more heavily penalized than cocaine. This disparity was largely based on unfounded fears surrounding crack vis-à-vis cocaine. While this type of sentencing disparity did not exist in Canada, it is still necessary to understand the irrationalities within American drug policy during the height of the War on Drugs to better understand the drug policies Canada was emulating during this time. The American War on Drugs also helped to condition our understanding of drug and drug consumption in Canada.

The Anti-Drug Abuse Act of 1986 coincided with American president Ronald Regan revamping the American War on Drugs which had been receiving less attention in the United States. Canadian Prime Minister Brian Mulroney stated in that same year that drugs were an

\footnotetext{
${ }^{85}$ Dimitri A. Bogazianos. 5 Grams Crack Cocaine, Rap Music, and the War on Drugs. (2012) New York: New York University Press 2012. At page 41

${ }^{86} \mathrm{Ibid}$ at pages 36-37

${ }^{87}$ Othello Harris and R. Robin Miller, Impacts of Incarceration on the African American Family, (New Brunswick, NJ: Transaction Publishers, 2003). At page 2014
} 
epidemic in Canada that undermined the Canadian economy and Canada's social fabric. ${ }^{88}$ Not only was there little evidence to support Mulroney's claim but drug use in Canada had been declining in recent years. This meant that Canada would have to make drugs a social and political issue even if there was not a major problem to solve. ${ }^{89}$ While Mulroney supported the American Government's views regarding drugs, Canada did not enact legislation nearly as aggressive as the United States and initially took a slightly different approach to drug policy.

Canada unveiled its new National Drug Strategy in May 1987 after holding consultations with community groups and agencies across Canada. The National Drug Strategy divided resources 70-30 in favour of demand reduction over supply reduction, and when the strategy was renewed for an additional five years, harm reduction was stated as the official goal. ${ }^{90}$ Despite having officially stated harm reduction as the main goal of the strategy and taking what appeared to be a different approach than the United States, the results were largely the same. At the end of the strategy in 1997, Canada seemed to be waging its own War on Drugs with as much determination as the United States. Evidence of this can be seen in Canada's renewed enforcement of marijuana, increasing convictions for cocaine, new police powers, more military involvement in relation to drugs, and the increasing rates of HIV and overdose deaths of intravenous drug users. ${ }^{91}$ This indicates a substantial difference between the official rhetoric in Canada and what was occurring. Canada never officially entered an American style War on Drugs, its official policy was to view drugs use as a medical problem and work towards harm reduction. Despite this official policy, Canada was following a similar strategy as the United

\footnotetext{
${ }^{88}$ Patricia G. Erickson and David L Haans supra note 24 at page 123

${ }^{89} \mathrm{Ibid}$ at page 123

${ }^{90}$ Ibid at page 123

${ }^{91}$ Ibid at page 123
} 
States with similar results. By 1997, the true nature of Canada's drug policy became more evident with the creation of the Controlled Drugs and Substances Act (CDSA). The CDSA combined cocaine, heroin, morphine, a variety of opiates without distinction and allowed for sentencing of up to seven years for possession and the potential of life imprisonment for trafficking. ${ }^{92}$ Marijuana possession and trafficking could carry harsh criminal sentences, police powers were expanded to allow for reverse sting operations and the need to obtain search warrants could be waived if obtaining one would be impractical. ${ }^{93}$ The passing of the CDSA ignored decades of research evidence regarding drugs and drug use in Canada in favour of an American style crackdown. While it is debatable if Canada ever fully moved away from the criminalization approach, the $C D S A$ ensured Canadian drug policy would be focused on criminalization over public health or harm reduction. Once again, drug use was viewed as a crime rather than social medical issue.

The $C D S A$ was initially created, in part, to ensure Canada was meeting its international obligations to combat drugs. Canada did not want to appear soft on drugs as opposed to the United States and also wanted to ensure it was in compliance with international treaty obligations. ${ }^{94}$ In response to critics who were concerned the CDSA would make public health and harm reduction initiatives more difficult and potentially illegal, the government's response was that the $C D S A$ would not be strictly enforced in all circumstances. ${ }^{95}$ Essentially policy makers were admitting that the CDSA may work against harm reduction and health initiatives and the

\footnotetext{
92 Ibid at page 124

93 Ibid at page 124

${ }^{94}$ Constance A. Nathanson, Disease Prevention as Social Change: The State, Society, and Public Health in the United States, France, Great Britain, and Canada (New York: Russell Sage Foundation, 2007). At page 198

${ }^{95}$ Ibid at page 198
} 
only way around this would be not enforcing the newest drug policy. When the Canadian government admitted that its policies work against medical and harm reduction approaches, it was admitting that it had_reverted to a criminalization approach.

\section{Canada's Current Drug Strategy}

The battle between harm reduction advocates and successive governments meant that harm reduction efforts in Canada were in difficulty. While InSite won its Supreme Court case and needle exchange programs were growing in popularity, the government never endorsed harm reduction instead choosing to focus on a criminalization approach. While Bill C-2 has come into effect it is difficult to determine what this will mean with a new Liberal government however, the current Prime Minister has spoken in favour of safe injection facilities as well as the legalization of marijuana. While it is too soon to determine what this will mean for Canada's drug policy, it would suggest that harm reduction could play a significantly larger role going forward.

\section{Differential Impacts of Canada's Drug Strategy}

While drug laws and drug prohibition in Canada apply to everyone regardless of socioeconomic status, the reality is that some populations are more impacted. Street involved or homeless populations are highly visible and their drug consumption is more easily seen and monitored than other more affluent populations. This means that while the law does apply to everyone, not all populations experience the impact equally. Street involved or homeless drug users may lack access to housing or shelter in which to consume drugs and they become visible and the association between homelessness and drug consumption begins to form. 
In a study of youth street involved drug users in Vancouver the researchers found that close to half of respondents had recently been stopped by police. ${ }^{96}$ While the interactions did not necessarily result in arrest, police confiscated drug consumption equipment in some instances and in other instances respondents reported what they perceived as violence from police. ${ }^{97}$ These interactions between street involved drug users and police illustrate how drug laws do not impact all drug users equally. These types of interactions may be part of a broader trend in which municipalities enlist police to help regulate visible signs of poverty through special exclusion..$^{98}$ Populations are pushed out of certain spaces to make room for gentrification or other projects in downtown areas that would otherwise be occupied by homeless or street involved populations. As a result, street involved people have fewer places in which to consume drugs without meeting police whereas non-street involved drug users remain unseen and unaffected. Furthermore, police in Canada frequently target poor and marginalized communities and groups. ${ }^{99}$ The criminalization of certain drugs criminalizes both the substance and the drug consumer. This disproportionately impacts groups that frequently interact with and may be targeted by police.

\section{Discussion}

Canada has always had a predominantly criminalization approach to drugs and drug users. There have been efforts and movements to try and change Canada's approach to drugs

\footnotetext{
${ }^{96}$ Lianping Ti et al., "Police confrontations among street-involved youth in A Canadian setting", International Journal of Drug Policy 24:1 2013. At page 48.

${ }^{97}$ Ibid at page $48 /$

${ }^{98}$ Forrest Stuart, 'From 'Rabble Management' to 'Recovery Management': Policing Homelessness in Marginal Urban Space”, Urban Studies 51:9 2014. At page 1909.

${ }^{99}$ Grace-Edward Galabuzi, “Canada's Economic Apartheid: The Social Exclusion of Racialized Groups in the New Century”, (Toronto, ON: Canadian Scholars' Press, 2006). At page 199.
} 
dating back as far as the 1950s. Despite continual evidence suggesting that the criminalization approach to drugs and drug users may not be the most effective, humane, or cost-efficient, Canada has always favored this approach at least from a legal perspective. Officially Canada did not enter a War on Drugs like the United States, yet the American approach has influenced Canada's public perception of drugs and drug users and had a significant impact on drug policy. Because drug laws targeted those who were already racialized as well as socially and economically marginalized, a false image of who was consuming drugs was generated. A broad range of people have always consumed drugs.

The next chapter will focus on how drug users have been viewed throughout history and how they view themselves. It will examine how the subjectivities of drug users can be shaped by those around them and how they internalize certain subjectivities imposed on them by others. 


\section{Chapter 2: Depicting the User}

The focus of this chapter is on how society's view of the drug user is subjectively constructed. This is not only society's views of the drug user and what subjectivity is imposed as a result but also the impact on the users' view of themselves. The last chapter looked at how the law and Canada's drug policy have viewed the consumption of certain drugs as criminal and inherently problematic and how these laws have had differential impacts on different populations. These populations face increased stigmatization because of perceived association with illegal drug consumption and social attitudes towards illegal drug use. These same populations, facing stigmatization, must navigate and understand their own drug consumption within this context. These populations are viewed as criminal drug users by dominant society. I will explore how drug consumption in economically, socially and racially marginalized populations is viewed differently than drug consumption among more affluent populations. Socially, economically and racially marginalized populations face increased stigmatization for drug consumption and consume drugs in the backdrop of this dominant discourse.

In this chapter, I will examine how the label of 'junkie' or addict is created, how this subjectivity is imposed on street involved drug users and the impact on how they view and define themselves. It will begin by looking at the meaning of subjectivity and how the drug user is depicted considering images in anti-drug ads, popular culture, and news reports. This will illustrate that depictions of drug users shape society's idea of what it means to be a drug user. Finally, I will look at how drug users have been depicted as victims, deviants, and alternatively how drug users are a subculture. 


\section{Subjectivity}

Subjectivity reflects how people relate to themselves and our way of understanding and enacting our existence as human beings in search of certain objectives, be it manliness, compassion, honor or any number of other potential objectives. ${ }^{100}$ Subjectivity is constantly changing and influenced by environmental factors that constantly alter our consciousness. Subjectivity involves how individuals view and define themselves, essentially how people constitute themselves. Subjectivity helps to regulate our notion of self as psychological beings and create a narrative about ourselves and our inner life that holds the secret to our true identities that need to be discovered if we are to live a true and honest life. ${ }^{101}$ The notion of the self is culturally created and relates to the network of values and social practices that regulate society at a particular time. ${ }^{102}$ Subjectivity is constantly changing as individuals re-imagine themselves and their broader relations with society.

Subjectivity is rooted in lived experiences as well as social forces and recognizes that everyone may interpret lived events and social forces differently. ${ }^{103}$ While everyone has their own experiences and understandings, these experiences and interpretations are rooted within the collective ideology and experiences of others. Subjectivity has as much to do with the collective reality and experience as it does with the individual interpretation of them. ${ }^{104}$ The collective

\footnotetext{
${ }^{100}$ Nikolas Rose, "Inventing Our Selves: Psychology, Power, and Personhood", (1998) New York, NY: Cambridge University Press. At page 24

${ }^{101} \mathrm{Ibid}$. at page 22

102 Tina Besley, and Michael A. Peters, "Subjectivity \& Truth: Foucault, Education, and the Culture of Self”, (2007) New York, NY: Peter Lang Publishing. At page 5.

${ }^{103}$ Arthur Kleinman, and Erin Fitz-Henry, "The Experiential Basis of Subjectivity How Individuals Change in the Context of Social Transformation"in Subjectivity: Ethnographic Investigations, (2007) Berkely, University of California Press. At page 53

${ }^{104}$ Ibid at page 53
} 
interpretation of an event or action can have as much impact on subjectivity as an individual's interpretation of the event or action. Further, the individual's interpretation is rooted in the context of the collective interpretation. Within the context of street involved drug users the collective interpretation of drug consumption may have as big an impact on how street involved drug users constitute themselves as their own interpretation.

Subjectivity is constantly changing; the constitution of self is an ongoing process rather than a fixed and stable idea. An individual may take on new subjectivities, or change their subjectivity as they reconstitute themselves in relation to both internal and external forces. Individuals do not exist in isolation and their subjectivities are always connected with outside forces. This may be an idea, a principle or the society they share with other individuals. ${ }^{105}$ As ideas, principles and society changes so may the subjectivities of individuals. While everyone within a society is a free and autonomous individual, these external factors help explain how an individual constitutes themselves and their place within society.

The subjectivity of the "drug user" is therefore a combination of how society has characterized and described drug consumption and how the individual understands their own drug consumption. Canadian drug law has always targeted certain populations and they are therefore believed to be associated with problematic drug consumption. Street involved populations are one of these groups. Drug consumption among street involved populations is depicted differently and is more stigmatized than within other populations in society. Street involved individuals who consume drugs are perceived as a problem, as people who cannot control their drug use or, as 'junkies'. Street involved individuals who consume drugs must do so

\footnotetext{
${ }^{105}$ Nick Mansfield, "Subjectivity: Theories of the Self from Freud to Haraway", (2000) New York, NYU Press. At
} page 3 
within this broader narrative about their drug use and navigate their own subjectivities in this context.

An examination of how drug users are portrayed allows a better understanding of external factors that may influence how people who consume drugs view themselves. Focusing on antidrug ads, popular culture and news stories, I will demonstrate how these external forces define what it means to be a drug user.

\section{Depicting the Drug User}

Drug users, especially street involved drug users, are commonly depicted by derogatory terms such as 'drug addicts', 'junkies', 'crack heads', 'lowlifes', and so on. These descriptions demonstrate the general disassociation from societal norms. Drug users are perpetual outsiders in society and therefore looked upon and treated differently than the dominant groups in society. This is different than depictions of other drug users, especially socially and financially elite drug users who may be characterized as 'rock stars' or 'partiers' rather than as drug addicts. Similarly, drug users may be viewed differently depending on what type of drugs they use. Users of marijuana or alcohol are not viewed the same as users of drugs such as heroin, cocaine or crack cocaine. Frequent users of marijuana may be depicted as 'stoners' or 'potheads' and frequent users of alcohol may be depicted as 'drunks' or as having a drinking problem. While each of these gentle depictions impacts the subjectivity of the user, my focus is also on street involved drug users who consume what would be considered hard drugs.

\section{Depictions of Drug-Users in Anti-Drug Ads}

The American website Rehabs.com provides a powerful example of how drug users are characterized in society. While it does not look at Canadian users, the narrative portrayed is 
consistent with popular narratives about drug users in Canada. The site has a section dedicated to the 'faces of addiction' that shows drug users before and after, along with their drug related criminal charges. ${ }^{106}$ The animated graphics show the drug user changing from a healthy and engaged person into an addict who is decrepit and unhealthy, having deviated from what an individual is supposed to look like. While this visual representation is intended to warn people of the harms of drug use, it does so by showing drug users as outsiders and members of the unhealthy population. This depiction of drug users is not unique or uncommon and is frequently accepted as the normal appearance. Drug users are expected to have hollow cheeks, dark eyes, haunted expressions, look wasted and decedent. ${ }^{107}$ This depiction of users shows them as being not only different from the rest of society but also as useless to society. ${ }^{108}$

Depicting the drug user as an unhealthy, unproductive societal outsider is not uncommon within North American anti-drug campaigns. Anti-drug messages in the United States during the 1980's and early 1990's was often sensational in attempts to prevent drug use. Anti-drug public service announcements needed to motivate viewers to watch the entire advertisement as well as to process a great deal of information quickly. One of the approaches was to target messaging according to sensation seeking levels, a biological characteristic linked to both communication and drug use. ${ }^{109}$ Individuals with high sensation seeking levels were believed to be more likely to experiment and use drugs. Similarly, individuals with high sensation seeking levels were

\footnotetext{
106 http://www.rehabs.com/explore/faces-of-addiction/

${ }^{107}$ Merrill Singer, J Bryan Page, "Social Value of Drug Addicts: Uses of the Useless”, (2014) Walnut Creek, CA: Left Coast Press. At page 15.

${ }^{108}$ Ibid at page 16.

${ }^{109}$ Lewis Donohew, et al., "Persuasive Communication and Drug Abuse Prevention", (1991) Hillsdale, NJ: Lawrence Erlbaum Associates Inc Publishers. At page 210
} 
believed to need stronger messaging to attract or hold their attention. ${ }^{110}$ Sensational anti-drug advertising was one way this could be accomplished. One of the more memorable anti-drug public service advertisements released in the 1990's depicted a full egg inside a shell representing the brain and a pan-fried egg representing a brain on drugs. The follow up ad showed a young woman who had ruined her kitchen with the frying pan, presumably to demonstrate drugs ruining her life along with her family and friends. While these advertisements are now often seen as punch lines by comedians, they were intended to send powerful anti-drug messages. While these ads are perhaps the most memorable they were not anomalies. Between 1989 and 1998 the Partnership for a Drug Free America released over five hundred anti-drug ads. ${ }^{111}$ Some of these advertisements were later criticized for misleading information and distorting the truth, that all drugs were equally harmful. ${ }^{112}$ Some have gone so far as to suggest the only accurate claim was that drug use can lead to a messy kitchen. While the claims in these advertisements have been challenged, the depictions of drug users have not. Many of the antidrug messages seen today continue to portray drug users as damaged and inherently different then the healthy non-drug using population. This fits within a larger narrative in which drug users reflect the images shown on Rehabs.com. This dehumanizes users and positions them as outside mainstream society.

The impact of these advertisements in reducing drug use is highly questionable. Many of the advertisements and public service announcements have been aimed at youth. It has been argued that anti-drug ads may have very little or no effect on drug use among youths and may

\footnotetext{
${ }^{110}$ Ibid at page 212

${ }^{111}$ Marc Oxoby, “The 1990s”, (2003) Westport, CT: Greenwood Publishing Group. At page 56

${ }^{112} \mathrm{Ibid}$ at page 56
} 
increase drug use in the long term. ${ }^{113}$ One theory is that despite the actual message, frequent exposure to drug ads and drug messaging creates the belief that more people are using drugs. Research supports this theory especially regarding marijuana use. Youth who frequently received anti-marijuana messages were more likely to believe their peers were using marijuana. ${ }^{114}$ Belief that marijuana use was frequent in a peer group could normalize the use of marijuana among social groups. ${ }^{115}$ Applying this same logic, one can see how the frequent negative depictions of drug users can create a belief about users. The intention of the ads was to prevent youths from using drugs, however by frequently portraying drug addict in a similar way, they helped normalize negative depictions of drug users. The portrayal of a drug users as un-healthy, decrepit and hollow continues within some anti-drug messaging seen today. This shows that this normative belief of what a user looks like continues today. While the intention of anti-drug ads was to prevent youths from using drugs, they have helped to create a consistent image of the drug user.

This depiction of the drug user creates a distinct visual image defined by the dominant group in society. This is part of the "othering" process of drug users which establishes the nonuser or non-addict as the norm against which the user must be compared. This division between user and non-user is largely fictitious and socially created. Those who are categorized as being users may in many instances not use drugs or use drugs with the same frequency as those categorized as non-users. The user is viewed as less worthy or less useful than the dominant non-

\footnotetext{
${ }^{113}$ Matthew B. Robinson, Renee G. Scherlen, "Lies, Damned Lies, and Drug War Statistics, Second Edition: A Critical Analysis of Claims Made by the Office of National Drug Control Policy", (2014) Albany, NY: University of New York Press. At page 248

${ }^{114}$ Douglas Evans, Gerard Hastings, "Public Health Branding: Applying Marketing for Social Change”, (2008) Oxford, United Kingdom: Oxford University Press. At page 157

${ }^{115}$ Ibid at page 157
} 
user group. ${ }^{116}$ This dynamic identifies non-users as the 'us' group and drug users as the 'them' group that is outside societal norms. "Othering" is comprised of behaviours and attitudes by the in-group that involve stereotypical ways of thinking, stigmatizing, social distancing, dehumanization, and justification of oppressive practices. ${ }^{117}$ People who are street involved are viewed as being linked with drug use. The result is that street involved people are viewed as drug users and treated as users or "junkies' regardless of whether they consume drugs or not.

\section{Depictions of Drug Users in Pop culture}

Images of drug users in pop culture vary depending on the socio-economic class of the user. Social and economic elites who use drugs are shown much differently than the poor and marginalized. Musicians, film stars, and athletes who use drugs such as cocaine may be viewed as rock stars or partiers. Similarly, lawyers or corporate executives who use drugs may not be depicted negatively. Popular culture does not view their drug consumption as problematic. Users who are not socially or economically advantaged do not receive the same treatment, they are depicted as junkies or addicts, outside mainstream society. Pop culture then simultaneously glamorizes socially and economically elite drug use while demonizing drug consumption by those who are not part of this group.

It is well known that Keith Richards, Mick Jagger, and Charlie Sheen have used illegal drugs during their careers yet their drug use is not condemned or shunned. Jay-Z, 50 Cent, and Snoop Dogg have all openly stated in their lyrics that they used to sell drugs. This type of drug use appears to not only be tolerated but perhaps even celebrated within popular culture.

\footnotetext{
${ }^{116}$ Singer, Supra note 5 at page 16.

${ }^{117} \mathrm{Ibid}$ at page 16.
} 
Arguments have been made that celebrity drug use may influence and encourage public drug use as people try and mimic the behaviour of celebrities without a full understanding of the harms associated with drug use. While this claim may be plausible, it is essentially impossible to definitively determine. ${ }^{118}$ Whether celebrity drug use has any impact on public drug use, the image of drug users who are not socially and economically powerful is much different than the images of those who are. This creates a sharp contrast between the pop culture depictions of elite level drug users and low-level drug addicts.

In his book 5 Grams Crack Cocaine, Rap Music, and the War on Drugs Dimitri Bogazianos looks at the relationship between crack and rap music. He argues that the image of Tony Montana in the 1983 movie Scarface has become symbolic within rap music. His drug kingpin status and ultraviolent death provide a readymade model of gangster heroism. ${ }^{119}$ Bogazianos also points out that rappers such as 50 Cent and Jay-Z have referenced their pasts as drug dealers and attempted to project themselves as drug kingpins. References to past drug dealings are not uncommon in rap music. Bogazianos argues that a close examination of the lyrics and imagery suggests much of this is related to lower level crack dealing than being an actual drug kingpin. ${ }^{120}$ Drug users were never depicted positively within rap music. The rise of crack cocaine in the United States, and the subsequent violence used in regulating crack markets, lead to the emergence of more lethal forms of violence within inner cities. Crack was the catalyst for this increase in lethal street level violence. Subsequently there have been powerful anti-crack norms that have emerged out of inner cities within the United States that make crack itself a dirty

\footnotetext{
${ }^{118}$ Neil McKeganey, “A-Z of Substance Misuse and Drug Addiction”, (2014) New York, NY: Palgrave Macmillan. At page 12

${ }^{119}$ Bogazianos, supra note 17 at page At page 1.

${ }^{120} \mathrm{Ibid}$ at page 55.
} 
word and vilify those who use it. ${ }^{121}$ Bogazianos argues that this vilification of crack users is because of crack's association with increasing lethal inner city violence that was often reckless and untargeted. ${ }^{122}$ This is reflected within rap music and that while rap music never called for non-violence, it did condemn reckless non-targeted violence. ${ }^{123}$ The reckless and untargeted violence condemned within rap music was associated with crack and became part of the anticrack norms emerging out of inner cities that vilified crack users. As such, rap music simultaneously celebrated drug sellers while condemning drug users. Crack users were then condemned by their own communities and peers. This "othering" process meant that communities and groups that crack users had previously associated with were now viewing them as outsiders.

Rap music is not the only pop culture medium in which drug addicts and drug users are negatively depicted. Myths and misconceptions about drugs and drug users often shape the way people think about these matters and this is reflected in film and television. This may serve to further misconceptions and myths that can shape public perceptions on what addicted and nonaddicted bodies are supposed to represent. ${ }^{124}$ In films that depict illegal drugs, drug users, and drug addicts, the addict is frequently devalued in comparison to the non-addict. This devaluation is amplified when the drug user is poor and racialized and being compared to middle class white non-addicts. ${ }^{125}$ Within these films sympathy for the addict is often aimed towards white middle

\footnotetext{
${ }^{121}$ Bruce A. Jacobs, "Dealing Crack: The Social World of Streetcorner Selling”, (1999) Boston, MA: North Eastern University Press. At page 128

${ }^{122}$ Bogazianos, supra note 17 at page 100

${ }^{123} \mathrm{Ibid}$ at page 100

${ }^{124}$ Susan C. Boyd, "Hooked: Drug War Films in Britain, Canada, and the U.S.”, (2010) New York, NY: Routledge. At page 91

${ }^{125}$ Ibid at page 91
} 
to upper class addicts. These individuals are seen as having hit rock bottom and finding salvation by defeating their addiction. ${ }^{126}$ Not only does this favorably depict white, middle class, and upper-class addicts and users but also individualizes the issue of drug addiction. Within this ideology the user must defeat or overcome their addiction to be re-integrated into mainstream society. This depiction ignores the poor and racialized users and may further marginalize people who consume drugs as people who simply have not overcome their addiction and re-integrated into mainstream society as this narrative suggests they should. These images can hide drug use among people who are economically empowered as they are part of dominant society and their drug consumption different from those who are socio-economically marginalized. Furthermore, many films that depict drug use favor a criminalization approach to drug use. ${ }^{127}$ The criminalization approach has largely failed and often disproportionately impacts poor and racialized users and addicts.

Film can be very powerful to elicit an emotional response and craft public opinion. Cinematic portrayals of drug use can influence people's perception of what it means to use drugs or what a person who consumes drugs is supposed to embody. Films represent an: "irresistible opportunity to feed the audience's appetite for spectacle, for something out of the ordinary - in short, for otherness". ${ }^{128}$ Films depicting drug users and drug addicts can fill this desire. These films typically portray drug users as being outside of normal social relations, essentially as the "others" in society. Film offers a unique opportunity to portray individual's unique character traits, nuances and idiosyncrasies. Films depicting drug users may show these unique traits,

\footnotetext{
${ }^{126}$ Ibid at page 91

${ }^{127}$ Ibid at page 92

${ }^{128}$ Taylor Donnelly, “'Just One Step Away': The Mad Other on the Contemporary Stage”, Otherness: Essays and Studies 2:2 2012. At page 1
} 
nuances and idiosyncrasies but frequently have similar depictions of what it means to be a drug user. This frequently involves accounts of the addictive process, deteriorating social relationships, desperate behaviour involving money, involvement in small crimes, painful withdrawals, betrayal of friends and family, and sex work. Drug use eventually results in the user suffering through both long and difficult withdrawal or continued addictions which ultimately results in death. ${ }^{129}$ These depictions in film can create especially powerful images of drug use within public consciousness. It takes less than one second for an image to be recognized by the viewer and one interpretation of this phenomenon is that volumes of knowledge and emotion can be evoked by a single image. ${ }^{130} \mathrm{~A}$ medium like film with constantly changing images has an almost unlimited ability to invoke knowledge and emotion in its viewer. ${ }^{131}$ This makes the depictions of drug users as the "other" in film a powerful factor in determining public perceptions of drug users. These depictions present drug users as unhealthy outsiders who are intrinsically different from the healthy non-drug using population. By depicting drug users as socially and economically marginalized, films further the perception that street involved individuals consuming drugs is problematic and the idea that street involved people who consume drugs are "junkies".

\section{Depictions of Drug Users in News}

Like film, news media can present powerful images and narratives of drug users that help shape public consciousness. While news media may not intentionally sensationalize drug use the same way films do, it can still be as powerful a force in shaping public perception. Unlike films,

\footnotetext{
${ }^{129}$ Singer supra note 5 at page 124

${ }^{130}$ Ibid at page 122

${ }^{131}$ Ibid at page 122
} 
in which the audience is aware they are watching a fictional and perhaps sensationalized account, news media is assumed to be factual and authentic. That the accounts witnessed reflect realities. The depiction of drug users can have a powerful impact on how drug users are viewed by society.

As an example, news coverage of crack cocaine during the 1980's in the United States was frequently inaccurate and helped create false narratives regarding crack users. During the mid-1980s frequent stories ran in major news sources such as Newsweek and Time regarding crack use and the dangers about crack, many greatly exaggerating its actual dangers. ${ }^{132}$ As the actual number of crack users began to decline, news stories continued to present distorted narratives and information. Over half of the news stories during the period featured black drug users and sellers even though the large majority of crack users at the time were white. ${ }^{133}$ At the same time arrests for drug use disproportionately targeted black users who made up $48 \%$ of arrests. ${ }^{134}$ This demonstrates that black users were far more likely to be arrested than white users. News coverage on crack cocaine certainly was not the only reason for this. Racism, socioeconomic situations and a variety of other factors were certainly involved, however this does demonstrate how news media portrayals of drug user can help perpetuate inaccurate narratives.

The impact of news stories in shaping public perceptions on drug users has been debated. While news may provide authentic and accurate information on drug users it does not necessarily receive a large viewership and may not create a lasting impression with viewers. News stories about drug use no longer occur as frequently and when they do they are often peripheral. When

\footnotetext{
${ }^{132}$ Michael D. Lyman, "Drugs in Society: Causes, Concepts and Control”, (2010) Burlington, MA: Anderson Publishing. At page 76

${ }^{133}$ Ibid at page 76

${ }^{134}$ Ibid at page 76
} 
given more in-depth coverage such as on 60 Minutes, stories involving drugs usually only take about 15 minutes and are constantly interrupted by commercials diluting the intensity of the stories message. ${ }^{135}$ Viewers are frequently consuming another media source while watching the news and frequently can only remember a couple of actual news stories afterwards. ${ }^{136}$ Film can leave a more powerful impression on viewers as the viewer is more likely to be completely engaged in the film and will be engaged for a longer period of time. This means that film could be a more powerful tool in shaping public perceptions of drug users than the actual news media. However, whether film is successful or not in this regard is up for debate. Despite the advantages of film in shaping public impressions, news media may still be more powerful in shaping the views of policy makers. During the crack scare in the United States, at the time when news stories were inaccurately portraying crack users and the dangers of crack, a very illogical drug sentencing law was passed. The Anti-Drug Abuse Act of 1986 created the 100:1 sentencing disparity between crack and cocaine meaning that to receive a five-year prison sentence an individual needed only five grams of crack compared to 500 grams of cocaine. This is not to suggest that the news media was solely responsible for this, but rather it illustrates that news stories can influence policy makers and can impact the law. While news stories about drug users are not as frequent, they can still have an impact in shaping perceptions about drug users and the subsequent laws.

These news reports on drugs, despite the inaccuracies, can play in important role in determining how people view both drug consumption and the user. This helps create the image

\footnotetext{
135 John Markert, "Hooked in Film: Substance Abuse on the Big Screen”, (2013) Lanham, Maryland: Scarecrow Press. At page viii

${ }^{136}$ Ibid at page viii
} 
of the "junkie". This can further public perceptions about a person who consumes drugs and may influence how people who consume drugs view themselves.

\section{Drug Users as Victims}

Drug users and drug addicts have also been characterized as victims of their addiction. The victim narrative avoids passing any moral condemnation on users for their lifestyle or drug use. Drug possession and drug use is viewed as a victimless crime because no other person is harmed by the criminal action. Society may be the victim because illegal drug use violates societal norms and appropriate behaviour but there remains no clear and identifiable victim. Instead of being a criminal, the user or the addict is viewed as a victim, someone in need of help. Unlike the criminal, the victim does not need to be punished. Drug laws may further marginalize and ostracize the user by criminalizing drug use therefore making the user a victim of both the law and of their own drug consumption.

Victimology looks at the relationship between the victims of crime, the offender, and the criminal justice system. Criminologist Hermann Mannheim, one of the first to begin studying victimology, suggested that the distinction between offender and victim is often blurry. Mannheim went on to theorize that the longer one spent examining the particulars of a crime, the more difficult it would be to place blame solely on the criminal. ${ }^{137}$ Attempting to spread the blame for a crime between offender and victim does have the potential to lead to victim blaming. Victim blaming is not: "Due to mere negative affect or the blind lashing out at victims but instead reflects systematic arguments (however groundless) pointing to the causes of the event, the obligations of the agents involved in the event, and the capacity of the victims to prevent the

\footnotetext{
${ }^{137}$ Ann Wolbert Burgess, et al., "Victimology: Theories and Applications”, (2011) Sudbury, MA: Jones \& Bartlett
} Publishers. At page 42 
event." ${ }^{138}$ This is frequently seen in cases of sexual assault where victims are perceived to be playing a part in their own attack or as having not resisted enough against the attack.

Viewing drug users and drug addicts as victims would mean that they are both the offender and victim. They are the offender in that they have committed a criminal act, however they could also be the victim. The law could then be blaming these same individuals by rendering them fully responsible for their addiction and for their victimization. Canada's drug policy has always favoured criminalization, despite attempts to change it therefore the law can then categorize users as criminals instead of victims.

To see addicts as victims, addiction must be considered a disease not a crime. This is the stance taken by the National Institute of Drug Abuse, an American Federal Research Institute focusing on drug abuse and addiction. The Institute defines addiction as "a chronic, often relapsing brain disease that causes compulsive drug seeking and use, despite harmful consequences to the addicted individual". ${ }^{139}$ Furthermore the Institute likens addiction to other chronic diseases such as diabetes, asthma, and heart disease which can all be successfully managed even if relapse occurs. ${ }^{140}$ This approach to drug use is similar to the medical model that was proposed in Canada in the 1950s but never gained enough traction to become the dominant policy approach. This type of approach to drugs may result in a different drug policy however it may still result in "othering" drug users and still situate the user as part of the unhealthy or diseased population that is separate from the healthy non-drug using population.

\footnotetext{
${ }^{138}$ Sana Sheikh and Meghan E. McNamara, "Insights from Self-Blame and Victim Blaming”, Psychological Inquiry 25:2 2014. At page 243

139 “Drug Facts: Understanding Drug Abuse and Addiction" National Institute of Drug Abuse, November 2012. Available online at $<$ http://www.drugabuse.gov/publications/drugfacts/understanding-drug-abuse-addiction $>$ ${ }^{140} \mathrm{Ibid}$
} 
Viewing drug users as victims allows users to change their subjectivity from that of being a criminal, or "junkie" to that of a victim. This subjectivity may be created externally of the individual, yet the individual may embrace this label or position. This position may be socially constructed, yet it can become an important part of how people who use drugs define themselves. The subjective position of victim may encourage sympathy from society, whereas the criminal or "junkie" garners contempt.

\section{Drug Users as Deviants}

When analyzing how drug users are portrayed and policy approaches to drugs and drug users, it is evident that the user is consistently situated as the outsider. The user is viewed as different from the rest of society, outside of societal norms. Even the most compassionate and well-intentioned policies and approaches may position the user as an outsider. To better understand and theorize the daily lives of users it is necessary to understand what being an outsider entails.

In Howard Becker's Outsider, Becker writes that every social group has a set of rules to abide by. These rules can be formally or informally enforced and those who do not follow these rules are outsiders. Those deemed as outsiders may not see anything wrong with the action that violates the rule and may question the authority of those who judge them as outsiders.

Conversely some may see their violation as wrong. ${ }^{141}$ What is considered deviant can be a socially constructed meaning that the idea that one action is deviant is not inherently natural. Some of these notions about what constitutes deviance are derived from ideas of what is and is

\footnotetext{
${ }^{141}$ Howard Becker, “Outsider", (2008) New York, NY: Simon and Schuster. At pages 1-2
} 
not considered normal behaviour. ${ }^{142}$ Another definition of deviance which Becker describes is the simple failure to obey group rules. ${ }^{143}$ The drug user can fit into both definitions as the user is depicted as being both unhealthy as well as in violation of societal rules. Becker goes on to write about how deviance is treated within society stating: "the treatment of deviance denies them the ordinary means of carrying on the routines of everyday life open to most people". ${ }^{144}$ For drug users, this means that the approaches to drug use such as forced treatment and potential jail time infringes on their ability to carry on daily routines.

To use drugs, one needs to purchase drugs. Becker argues that this entails gaining access to a trusted drug dealer. Since the selling of drugs is prohibited, anyone selling drugs needs to trust the purchaser, and the user if the purchaser supplies other users, not to endanger them. Generally, this means that a purchaser must have a connection to gain access to drug dealers. ${ }^{145}$ Becker argues that the more one becomes seen or identified with groups that use drugs the more trustworthy they become and they can gain access and acceptance of drug sellers more quickly and easily. ${ }^{146}$ This makes them insiders within a specific group of what may be considered deviants.

If someone is labeled as being a deviant they may internalize this label and act in accordance with societal beliefs of what this label means. Labeling theory suggests that when a person is labeled as a deviant they may accept and internalize that label and continue engaging in

\footnotetext{
${ }^{142}$ Ibid at page 7

${ }^{143} \mathrm{Ibid}$ at page 8

${ }^{144} \mathrm{Ibid}$ at page 35

${ }^{145} \mathrm{Ibid}$ at page 64

${ }^{146} \mathrm{Ibid}$ at page 64
} 
activity that is consistent with that label. ${ }^{147}$ Essentially individuals will behave in ways they believe that others around them believe they should behave. ${ }^{148}$ Individuals may start to behave in ways consistent with societal expectations of their assigned label. This means that labeling can have a substantial impact on individual subjectivities. For the drug user, this means that the labels applied to them such as 'junkies', 'crack heads', 'lowlifes', 'drug addicts', can impact the behavior of the user. The depictions of user that are perpetuated within society and help to define what these terms mean could have a significant impact on the behaviour of users.

\section{Drug Users as a Subculture}

Subculture is made up of a smaller group within a larger culture. Subcultures can often be comprised of subordinate groups that operate outside the norms of the dominant culture. ${ }^{149}$ These groups can include the punks, the rockers, or drug users who are "dismissed, denounced, and canonized; treated at different times as threats to public order and as harmless buffoons". ${ }^{150}$ Within these subcultures certain objects: "take on symbolic dimension, becoming a form of stigma, tokens of self-imposed exile". ${ }^{151}$ For example the syringe that intravenous drug users inject with may take on symbolic meaning within drug using subcultures. Subcultures may also define their own rules and norms which may differ from the dominant culture. For instance, graffiti may be viewed much differently within certain subcultures than by the dominant culture. Similarly, drug use may be seen differently by certain subcultures than by the dominant culture.

\footnotetext{
${ }^{147}$ Sean Maddan, "The Labeling of Sex Offenders: The Unintended Consequences of the Best Intentioned Public Policies", (2008) Lanham, Maryland: University Press of America. At page 22

${ }^{148}$ Ibid at page 22

${ }^{149}$ Dick Hebdige, "Subculture”, (2003) New York, NY: Routledge. At page 2

${ }^{150}$ Ibid at page 2

${ }^{151} \mathrm{Ibid}$ at page 2
} 
Certain subcultures can also be deviant. For instance, intravenous drug users are considered a threat to public safety, public order and to what is considered culturally acceptable. Street involved drug users may be viewed as part of the intravenous drug user group even if they do not inject drugs. People who are street involved are frequently associated with drug use and as part of the street involved drug user subculture, regardless of whether they consume drugs. Rules and norms exist within these subcultures. While street involved people may be scorned, degraded and pitied by dominant society, street involved drug users may share many of these same feelings towards conventional society. ${ }^{152}$ Furthermore drug users may have certain values that help to underpin the value of getting high. ${ }^{153}$ This suggests that street involved drug users view drug consumption differently than the dominant society. Street involved drug users have their own norms and values related to drug consumption that are independent of the norms and values of the dominant culture that includes non-street involved drug users.

\section{Summary}

The depictions of drug users within society are created through a variety of media sources such as anti-drug public service announcements, popular culture as well as news media reports. This has helped to create an image of what a drug user resembles and what the user or the addict represents. The portrayal of the user as an outsider, a deviant, or a victim are reinforced through law and through the labeling of drug users. This can impact society's perception of what it means to consume drugs or to be a "junkie", as well as the drug users' depiction of themselves.

\footnotetext{
${ }^{152}$ Samuel R Friedman et al. "AIDS Health Education for Intravenous Drug Users", Health Education Quarterly Winter 1986. At page 385

${ }^{153} \mathrm{Ibid}$ at page 385
} 
Drug users as a subculture may have a different view of deviance and norms than dominant culture. This subculture can consist of users and the addicts which are viewed as outsiders or deviants in dominant society. This can result in a subculture of deviants with different norms and values.

There is also a tendency to group street involved drug users together with drug addicts. This may be completely inaccurate. While some street involved users may fulfil the medical definition of an addict, this may not be true of other street level drug users, however they are viewed as a homogenous group. Viewing all street involved drug users as drug addicts, "junkies", or "crack heads" imposes a subjectivity. Street involved drug users may view drug use differently than non-street involved drug users. However, they may both internalize and define themselves by the subjectivity imposed upon them by the dominant group. 


\section{Chapter 3: Relationships and Subjectivities Among Street Involved Users}

This chapter will look at how street involved men who use drugs regulate themselves. It will examine many issues about how drug users define acceptable and unacceptable drugs use, why certain drugs are used and how users depict themselves. Finally, I will look at how social groups and hierarchies are formed in relation to drug use and the impact that drug use has on the formation of these groups.

\section{Acceptable and unacceptable drugs use}

People who use drugs define what they consider to be acceptable and unacceptable drug use and navigate this dichotomy accordingly. In Karen Foster and Dale Spencer's article, they found that homeless and street involved youth drug users would draw boarders around what they considered to be acceptable and unacceptable drug use. One of the ways in which users would differentiate between acceptable and unacceptable drug use was based on the type of drug being consumed. Their study found that recreational drugs like marijuana are more acceptable, safer, and more normal than hard drugs like crack cocaine". ${ }^{154}$

This was like Hilary Pilkington's research on youth drug users in Russia. Pilkington found that individuals understood potential harms or risks of different drugs and differentiated between drugs. Pilkington's research found: "that young people's drug choices are framed largely within dominant discourses of drug use". ${ }^{155}$ Pilkington also found that respondent's

\footnotetext{
${ }^{154}$ Foster, Karen and Dale Spencer, “'It's just a social thing': Drug use, friendship and borderwork among marginalized young people”, International Journal of Drug Policy 24 2013. At page 229

${ }^{155}$ Hilary Pilkington, "In good company: risk, security and choice in young people's drug decisions", The Sociological Review 55:2 2007. At page 374
} 
friendship groups were their "primary point of contact with drugs". ${ }^{156}$ While Pilkington found that users' decisions about drug use were framed within the dominant discourse, they also engaged in sharing information through friendship groups. This type of sharing garnered a "qualitatively different kind of knowledge" that was evaluated less in terms of accuracy and more in terms of its "mutually binding quality". ${ }^{157}$ Foster and Spencer showed that street involved young people would differentiate between acceptable and unacceptable drug use often based on the type of drug. Recreational drugs were considered more acceptable than harder drugs. Pilkington showed that youth had a cultural knowledge of the risks or harms associated with different drugs and that this knowledge was situated within the dominant discourse on drugs and drug use. However, information regarding drugs and drug use gained through informal means, namely friendship groups, was also considered valid information regardless of its accuracy. Combined, these studies show that people who are consuming drugs have a cultural knowledge of drugs and make distinctions between different drugs based on this knowledge.

Unlike the studies done by Foster and Spencer or Pilkington, my research was solely about street-involved adult males and did not include youth or female users. Despite these important differences, the research produced similar results. Almost all respondents spoke about smoking marijuana or having smoked marijuana at some point. Respondents spoke of smoking marijuana as a very routine and ordinary thing. None of the respondents seemed concerned about the potential impacts of marijuana. Respondents who had previously used what they considered to be considered hard drugs and in some instances self identified as previously struggling with addiction, still smoked marijuana on a regular basis.

\footnotetext{
${ }^{156}$ Ibid at page 381

${ }^{157}$ Ibid at page 385
} 
Rick, who had recently been released from a halfway house after getting out of the penitentiary and who, at one point in his life, used intravenous drugs daily, strongly identified as being a recovering drug addict. When asked how he would describe himself, Rick responded: "I'm struggling with addictions but I'm winning". When asked what drugs he currently uses, Rick responded "I smoke marijuana daily, I'm struggling with speed right now but I think I got a handle on that now". While Rick clearly viewed his use and subsequent addiction to speed as an issue, he did not see problems with regular use of marijuana. This supports Foster and Spencer's findings that drug users will differentiate between soft and hard drugs. Rick had assumed the subjective position of the recovering drug addict and accepted the cultural and social ideas of what it meant to be a drug addict and defined himself in opposition to these ideas. He was no longer an addict and could no longer be defined by his drug consumption. He was no longer a “junkie". ${ }^{158}$

Brent who had come to the shelter after the passing of both his parents, whom he had given up his career to care for, also differentiated between hard and soft drugs. When asked what types of drugs he had used in the past he responded: "I used to do coke (cocaine) back in the 80's but I don't do that stuff anymore, I just stick to a joint". Brent would also appear to be drawing a boarder between hard drugs such as cocaine and soft drugs such as marijuana.

While marijuana was considered acceptable, there were drugs that some respondents would never use. Intravenous drugs were often avoided and treated as being different or unacceptable even among respondents who used harder drugs. Adam who occasionally uses 
cocaine, although he used to use it more frequently when he was working long hours, would never use intravenous drugs.

Interviewer: Are there any drugs you won't use?

Adam: Needles I would never use.

Interviewer: How come?

Adam: I'm scared of needles and I've seen too much things with needles. Even going into grade four there was needles in the bathroom, grade four I was like I always saw them and I was scared of them.

Adam would use hard drugs, namely cocaine, but refused to inject drugs. On the surface Adam's rationale for refusing to use intravenous drugs seems to be fear of needles. However, upon a closer consideration, his rationale is very telling. He spoke of seeing "too much things with needles" and that he used to regularly see needles in the bathroom in elementary school. This is like Pilkington's finding of youths gaining qualitative information about drugs from their peer groups. While Adam did not necessarily learn about the harms or potential harms of intravenous drug use from his peer group, he developed his own qualitative knowledge of needles through first-hand experience. This reveals that what appears as a simple fear of needles was part of a much larger narrative about Adam's experiences with drug use.

Other respondents refused to use intravenous drugs because of the harms injection drugs had caused to others. Respondents had witnessed first-hand the impacts of intravenous drug use. Thomas, who grew up an hour outside of Ottawa and had recently been released from jail for selling drugs, still smoked crack cocaine but would never use intravenous drugs. This was based on his own life experiences with intravenous drugs and seeing the impact on users. 
Interviewer: Are there any drugs you won't use?

Thomas: Heroin or anything like that.

Interviewer: How come?

Thomas: I had a lot of friends die from it.

Thomas' narrative to avoid a particular drug, based on seeing its impact first-hand, was not unique. Pilkington found that youth drug users engaged in information sharing within peer groups and make decisions based on this information.

Intravenous drugs were more stigmatized among respondents than any other drug. Those who used intravenous drugs were often described as being unhealthy and unsanitary. Intravenous drug users were often described as a "junkie". The "junkie" is a particularly powerful identity that describes the most negative perceptions of intravenous drug users. It "encompasses all of the dirtiness, disease, deviancy, dangerousness, laziness, and absence of will that are so commonly associated with injecting drug use". ${ }^{159}$ During interviews with women in Australia who used intravenous drugs, Peta Malins found that once an individual was considered a "junkie" they were viewed and treated differently. People seek to avoid the "junkie" and certain spaces become off limits. ${ }^{160}$ Malins also found that respondents she interviewed would seek to avoid being perceived as a "junkie". Almost all respondents I interviewed avoided being perceived as a "junkie". Their decisions of which drugs were acceptable or unacceptable were often to avoid becoming a "junkie".

\footnotetext{
${ }^{159}$ Peta Malins, "Body-Space Assemblages and Folds: Theorizing the Relationship between Injecting Drug User Bodies and Urban Space", Journal of Media \& Cultural Studies 18:4 2004. At page 489

${ }^{160} \mathrm{Ibid}$. at page 490
} 
Scott used to consume cocaine, crack and speed but would never use intravenous drugs.

Interviewer: Were there any drugs you never used?

Scott: I would never stick a needle in my arm.

Interviewer: How come?

Scott: I don't like them and I seen what it does to other people, you get the itches and they get scratching and you get sores all over your body. It's not a good thing.

Scott's description of the itches and scratching and sores from intravenous drug use are associated with the unhealthy and dirty "junkie". Scott differentiated between the user and the "junkie" and was unwilling to consume in a way he associated with the "junkie". While drug consumption was acceptable, being a "junkie" was unacceptable. Scott and Thomas both saw the impacts that intravenous drug use had on others and decided not to use them. Thomas and Scott learned about drugs and drug use from their peer groups. There is however an important distinction in the way this information is shared. Rather than gaining qualitative knowledge through a friendship group, both Scott and Thomas gained knowledge by witnessing other users. Because both Scott and Thomas had a great deal of experience with drugs and were drug users, they may have more direct knowledge than the youths interviewed by Pilkington. This suggests that qualitative information gained through experiences with drugs are helping to shape the decisions users make regarding drug use and drug using practices.

Among respondents who use or had used intravenous drugs, there were still instances in which they would avoid certain drugs, most commonly heroin. Warren, a former intravenous cocaine user said that at one point he had injected daily, but would never use heroin. 
Interviewer: Where there any drugs that you wouldn't use?

Warren: Heroin.

Interviewer: And how come you wouldn't use heroin?

Warren: It's just to me that was the last step and I don't think I was ever ready to go that step.

The use of hard drugs and even intravenous drugs was acceptable for Warren yet the use of heroin was not. Warren spoke of heroin being "the last step", the use of heroin meant he would move beyond his current drug consumption. To use heroin meant taking on a new subjectivity, one that may be more defined by drug consumption. Instead of being a person who was consuming drugs, the use of heroin or Warren's final step, meant becoming the "junkie". This was similar for Sam, a long-time crack cocaine user who would occasionally inject but preferred smoking. While Sam was willing to use crack cocaine intravenously, he would not use heroin.

Interviewer: Are there any drugs you won't use?

Sam: I don't want to do the yellow stuff; you know what I'm talking about?

Interviewer: The yellow stuff?

Sam: Yah, you know the stuff important people go on methadone for.

Interviewer: Heroin?

Sam: Yah that's yellow, that's brown I mean.

Interviewer: How come?

Sam: I don't know I just don't think that's the kind of thing. Sometimes you got to think is that too overpowering you know, I mean you get hooked on it much 
quicker I don't know. I mean I've been doing crack cocaine since the 70's I just never went to the other things.

Interviewer: Have you ever tried it?

Sam: No, and I've had opportunities and I've said so I don't think it's for me.

Much like Warren, the use of hard or even intravenous drugs was acceptable to Sam. However, he was concerned about heroin's addictiveness and unwilling to use it. Sam expressed concern about becoming hooked on heroin. Being addicted to heroin meant that Sam's identity may become more closely linked to drug use. This new identity was also linked with the "junkie" who is dependent on drugs rather than a person who enjoys consuming drugs. Foster and Spencer found that street involved youth would use the notion of soft and hard drugs to distinguish the borders between acceptable and unacceptable drug use. Among respondents I found two borders that separated acceptable and unacceptable drug use. These boarders depended on consumption habits. For users who did not use intravenous drugs, the boarder was the use of needles. Injecting drugs was unacceptable drug use and they would negatively view those who used needles. For those who did use intravenous drugs, the boarder was the use of heroin. Using heroin was unacceptable.

Acceptable and unacceptable drug use frequently related to how respondents constituted a "junkie". Respondents spoke negatively about intravenous drug use and depicted the use of needles in terms associated with society's idea of a "junkie". The "junkie" is heavily stigmatized and a powerful identity that implies dirtiness, disease, deviancy, dangerousness, laziness, and absence of will. The avoidance of this subjectivity could often be seen in how respondents 
differentiated between acceptable and unacceptable drug use. Unacceptable drug use was perceived to be part of the "junkie" identity.

The boundaries between acceptable and unacceptable drug use among respondents who consumed intravenous drugs were also related to the "junkie" identity. Heroin was described as the last step and more addictive than other intravenous drugs such as crack cocaine. They tied the subject position of "junkie" to the use of heroin. Neither respondent was willing to use heroin and take on the identity of the "junkie". The subject position of the "junkie" and the avoidance of this identity plays an important role in how street involved men are determining acceptable and unacceptable drug use.

\section{Acceptable and unacceptable places to use drugs}

Certain places may be considered acceptable for drug consumption. In their study on youth drug users, Foster and Spencer found that: "borderwork involves temporal and spatial dimensions, delimiting acceptable times and places for drug use". ${ }^{161}$ The workplace was generally considered an unacceptable time and place for drug consumption among interviewees in Foster and Spencer's study. This suggests an internal regulation of space in which certain spaces are acceptable for drug consumption and other spaces are not.

Certain geographic spaces may be associated with drug consumption. It is frequently assumed that drug consumption is common in low income urban areas and they are viewed as areas where issues related to drug consumption are likely to occur. ${ }^{162}$ These geographic spaces are frequently ones of isolation and underdevelopment, the identifiable difference between these

\footnotetext{
${ }^{161}$ Foster and Spencer Supra note 1 at page 229.

162 Barbara Tempalski, and Hilary McQuie, "Drugscapes and the role of place and space in injection drug userelated HIV risk environments”, International Journal of Drug Policy 4:13 2009. At page 7.
} 
geographic areas and other areas are important in maintaining social boundaries and differences. ${ }^{163}$ Both these geographic areas and the people who occupy them are separate from those who occupy higher income more developed areas. These are the slums, the ghettos, or the projects: areas viewed as socially and economically less important. The people who live in these areas can be similarly marginalized, and their drug consumption seen as different due to their socio-economic status. These areas are geographic spaces that the "junkie" inhabits.

Mircea Eliade looked at how the idea of a sacred space is created. Although Eliade looked at the creation of scared space in the religious sense, the concepts are relevant to this study. Eliade identifies five key components of sacred space, the most important for this study being that sacred space: "marks a break in the homogeneity and amorphousness of hitherto undifferentiated space". ${ }^{164}$ Sacred space is different from other space and has a definitive form for a definitive purpose. While this study did not consider sacred spaces in the religious sense in some instances street involved drug users view certain spaces differently and the idea of sacred space may help to understand how these spaces are constituted and why using drugs in these spaces was unacceptable.

Among respondents who were active drug users, there was a group who would not consume drugs at or near the homeless shelter. This was true for both users of hard and soft drugs. Jeff describes himself as a recreational user. He predominantly smoked marijuana but would occasionally use harder drugs in social setting where they were available. He also

163 Ibid at page 7

${ }^{164}$ Larry Shiner, "Sacred Space, Profane Space, Human Space”, Journal of the American Academy of Religion 40:4 1972. At page 426. 
adamantly refused to use any intravenous drugs. For Jeff, the shelter was a place he did not want to get high.

Interviewer: Are there any places you tend to use (drugs) in more than others?

Jeff: For pot, you mean?

Interviewer: Yah, where you will or won't smoke it in?

Jeff: Well I mean like particularly if I was to go and pick up some pot right now I wouldn't smoke it around here.

Interviewer: Not around the shelter you mean?

Jeff: Not even close, I wouldn't go anywhere near this place with it because I

live here I don't want to get kicked out and I appreciate what they've done for me here. So out of respect for that I would go to another area or move around or go to a park or something like that and smoke it there or something like that.

Jeff would not smoke marijuana around the shelter because he lived there, it was his home. The notion of home may not always be a specific geographic location but rather a private space of safety and comfort. ${ }^{165}$ The "junkie" lives in socio-economically marginalized and isolated areas and uses drugs in these same areas. By refusing to use drugs in these areas Jeff is actively avoiding the label of "junkie". He is separating himself from that highly stigmatized group and is establishing his home as a place where he will not consume drugs. Most of the men

\footnotetext{
${ }^{165}$ Leslie Robertson, “Taming Space: Drug use, HIV, and homemaking in Downtown Eastside Vancouver", Gender, Place \& Culture, 14:5 2007. At page 529.
} 
I interviewed had a general awareness that this shelter was more tolerant towards drug use than others, and less likely to kick them out for drug use. Ryan, another respondent, said: "You can smoke a joint and the maximum they can put you is 15 minutes out so it's not as stressful". Regardless of the shelter's policy or attitude towards drug use some respondents still chose not to use drugs near the shelter. Jeff was the most overt about his rationale for not consuming drugs around the shelter. Other respondents left the area when consuming drugs less out of a respect for the shelter and more out of habit. For instance, Brent reported to usually smoking marijuana with friends or in a park.

Interviewer: What are you comfortable sharing about how you get drugs when you're going to use them now?

Brent: I don't understand what you mean.

Interviewer: Like if your going to get a joint.

Brent: Oh, well I've still got buddies in town, I just give them a call.

Interviewer: And it's just your buddies who you smoke pot with?

Brent: Yah a couple buddies here or there, either that or go take a walk read a book in the park and smoke one there.

Brent and Jeff would both be considered soft drug users who did not consume around the shelter. Neither Brent nor Jeff ascribed a great deal of importance to the places they smoked marijuana but would not smoke around the shelter. Moral geography is the idea that certain 
people, things, and practices belong in certain spaces and not in other spaces. ${ }^{166}$ The shelter represented home to Jeff and this was a space where drug consumption was unacceptable. Brent also avoided smoking around the shelter, though placed less emphasis on it being home. For both men, drug consumption did not belong in this space. Among hard drug users there appeared to be much greater importance on the spaces at which they were consuming drugs. Street involved hard drug users reported wanting a safe space in which to consume drugs. The space they occupied when consuming was very important. For Warren that meant always using at home where he felt safe.

Interviewer: Were you using them [cocaine] indoors or outdoors?

Warren: Indoors, I always shot at home, I didn't feel safe doing in anywhere else.

It was clearly important to Warren where he consumed drugs since he only felt safe at home. The feeling of safety one has when home was important for Warren. In this instance home was both a specific physical location and emotional space that provided safety, privacy, and comfort. Similarly, Sam reported wanting to be indoors in an apartment or hotel before consuming drugs.

Interviewer: When you're using where do you usually use them?

Sam: Somebody's apartment or something, somebody's house, I don't like going to the hotel because it costs money again but if I have to.

${ }^{166}$ Tim Cresswell, "Moral Geographies" in Cultural Geography: A Critical Dictionary of Key Ideas, (New York: I.B.Tauris, 2007). at page 128 
Interviewer: If you're using in somebody's apartment or house is it usually someone you know?

Sam: Yah someone I know. I have to then also include them in the thing so there's less for me but that's what I have to do to enjoy it when I'm there.

While Sam did not like including others in his drug consumption, he was willing to involve them to gain access to the space he wanted to consume in. Much like Warren, the space in which he was consuming drugs mattered to him. It was a space that was distinctive and safe, allowing them to consume drugs as desired.

Space was an important factor for users who consumed outdoors. Guy, a former heroin user who lived on the streets when he was using, reported that he usually consumed outdoors. Despite using outdoors, Guy still maintained certain spaces in which he would consume drugs, like those who used indoors.

Guy: Usually you get into a nice little dark spot where you know you can hear.

Parks are really good, get in among the bushes. Doesn't take long till you're done, clean up and move on. You didn't want your little hiding spot to be found if you leave needles all over.

Interviewer: Did you have any rituals around how you would find that spot?

Guy: No just had to be a nice quiet out of the everybody's way that had like a high point you could get cover.

Interviewer: A high spot you said?

Guy: Yah where you can see everybody. 
Interviewer: Would you usually use the same spot every time?

Guy: No, you had five or six different spots you never stayed in the same spot too long cause then people might notice you and then they start looking to see if you're there the next day. If you are then word of mouth gets around and next thing you know there's other people coming around.

The consistent theme among hard drug users was the desire for safety when consuming. They did not report having a sacred place in which they would not use but rather a desire for a safe space to consume. Only Warren had the financial resources to access a specific place to regularly consume on his own. Guy had several outdoor spaces he considered safe that he regularly used when consuming. Sam would involve others by sharing his drugs to gain access to certain spaces. This demonstrates another distinction between hard and soft drug users interviewed: soft drug users considered the shelter a sacred place and would leave the area when using drugs whereas, for hard drug users, the most important consideration was to use in a safe place where they would not be disturbed.

This supports Melissa Butcher's study of space and subjectivity. Butcher found that on Delhi's metro prevailing social norms and constraints largely controlled behaviour among riders. Social boundaries were redrawn around stereotypical judgements and people sought out those that were like them. This action "re-asserts boundaries of social order extending from subjective understandings of place and space use" ${ }^{167}$ Spaces can be constructed in ways that social interactions can reproduce certain order and reinforce certain norms. This can impose

\footnotetext{
${ }^{167}$ Melissa Butcher, "Cultures of Commuting: The Mobile Negotiation of Space and Subjectivity on Delhi's Metro", Motilities, 6:2 2011. At page 251.
} 
subjectivities onto people that exist within dominant discourses that individuals may not otherwise identify. When individuals are alone in spaces they may no longer be bound by social norms and subjectivities are less easily applied. By using alone Warren, Guy, and Sam could avoid the imposed subjectivities placed on intravenous drug users.

Among respondents who used intravenous drugs, all chose to do so alone. They removed themselves from social norms and often applied to intravenous drug users, namely the "junkie". Their drug consumption was no longer judged within the dominant discourse of intravenous drugs allowing them to more freely define their own identity and subjectivity.

\section{Intravenous Drug Consumption}

Street involved drug users make up a specific subculture that may operate outside of society's dominant discourse and create their own rules regarding drugs and drug use. As described earlier, respondents would often draw boarders around what was acceptable and unacceptable drug consumption based on what it meant to be a "junkie". Intravenous drug use was the most frequent distinction. Respondents did not use intravenous drugs for a variety of reasons ranging from a fear of needles to negative life experiences. Some respondents described those who injected drugs as part of the out-group, engaged in something worse and different from their own consumption habits. Intravenous drug use was outside of what was considered acceptable and the users were also outside the social norms within the street involved drug user subculture. Using needles meant going beyond what was acceptable, moving from drug consumer to being a "junkie". When Jeff was asked about his drug use he was adamant that he not only avoided using needles but also tried to avoid people the used intravenous drugs.

Interviewer: What type of drugs have you done in the past? 
Jeff: Everything except anything you have to shoot or inject so... there's pot, there's coke, hashish, the mild stuff really. I stay away from people that do needles and that kind of stuff.

Interviewer: Is there any reason you always avoided it?

Jeff: Specifically, because its dirty and I don't want to get AIDS or I don't like needles, just those types of people. I was exposed to it recently over the weekend I mean this girl was like poking herself and then she turned around dropped her drawers and asked everyone everybody to have sex with her and it didn't matter who was there she just...it was disgusting...like she's covered in blood asking for sex...no thank you.

In Jeff's view, intravenous drug users as a group should be avoided. He described them as both unsanitary and unhealthy, traits frequently associated with the "junkie". Jeff associated needles with the "junkie" and did not want to associate. He positioned himself positively in comparison with intravenous drug users or "junkies", a subjectivity he viewed as being undesirable.

John described himself as a recreational user. He had previously struggled but had overcome addiction to phencyclidine, commonly referred to as PCP or angel dust. He came from a broken home and refused to use intravenous drugs. John's narrative involved the struggle to find daily motivation and the challenges to not give up. Using intravenous drugs, or even smoking crack cocaine represented giving up hope for John, something he remained unwilling to do.

Interviewer: Are there any drugs you won't use? 
John: I won't touch crack, I won't touch crystal meth, I won't touch PCP

anymore, won't touch needles, won't touch crack pipes,

Interviewer: How come you won't use those ones?

John: I don't have much left of anything to hold on to I just don't, as soon as I start smoking crack I'll have nothing. I don't really have any reason to wake up every morning as it is now. I start smoking crack or start shooting myself with some fucking crap or another I won't have any reason to live, there won't be any fucking purpose. After everything I've fucking been through, I come away from a broken home my parents tried to kill themselves when I was fucking living in the same house. They abused me for fucking years, I ended up in a drug and rehab when I was 15, I asked a fucking lawyer to put me in jail when I got in trouble with the law because the lawyer walked into the little fucking room all that time ago and said you can go home with your parents. I have enough problems, I start doing shit like that, I know better, I would just see that as completely giving up on life.

For John, the use of intravenous drugs or crack cocaine were unacceptable drug use. His positive social identity was tied to avoiding these drugs and drug consumption techniques. He associated the use of intravenous drugs with giving up, hopelessness and laziness frequently associated with the "junkie". Avoiding the "junkie" identity was important to John and much like Jeff he positioned himself as different from and above the "junkie". 


\section{Social dynamics of drug use}

Two patterns emerged from questions about the social nature of drug use. Some would use drugs with others and some would predominantly use by themselves. Prior studies on the social networks of drug users have suggested that drug using social groups are relatively small, usually no more than five people in one social group. ${ }^{168}$ The social stigma surrounding drug use and subsequent shame may also increase drug user's isolationism and contribute to their smaller social groups. ${ }^{169}$ These smaller social groups help create the drug user subculture and have different beliefs and views on drug and drug use than the dominant discourse. ${ }^{170}$ This allows individuals to create their own identities shaped by the norms and values of the subculture rather than by the norms and values expressed within the dominant discourse. A street involved person who uses drugs may be labeled a "junkie" by the dominant discourse, yet they may have an entirely different subjectivity that has been crafted by the norms and values of their subculture. This allows individuals a much greater ability to define their own identity.

Respondents who reported using with others most often chose small groups, and occasionally used with one other person. In certain instances, drug use was described as a social activity among friends as a routine element of friendship.

Interviewer: Do you usually do them alone or with a couple of buddies?

\footnotetext{
${ }^{168}$ Trumbetta, Susan, et al., "Social networks and clinical outcomes of dually diagnosed homeless persons", Behaviour Therapy 30 1999. At page 409.

${ }^{169}$ Spooner, Catherine. "Impacts of stigma on HIV risk for women who inject drugs in Java: A qualitative study", International Journal of Drug Policy 26:12 2015. At page 1247.

170 Jan Keene, “Understanding Drug Misuse: Models of Care and Control”, (2010) New York, New York: Palgrave Macmillan. At page 132.
} 
Brent: Usually with a couple buddies.

Interviewer: How did you meet the people you do it with?

Brent: Through here.

Interviewer: Are they buddies of yours?

Brent: Just guys that I met here like there's a certain amount of people, it's an older crowd so no bull crap just level headed guys.

Interviewer: What type of relationship do you have with those guys?

Brent: I consider a few of them my brothers.

In other instances, the shared drug use was described as an integral part of friendship. The sharing of drugs helped to ensure the friendship and ensured access to drugs. In Vendula Belackova and Christian Alexander Vaccaro study of friendship among marijuana users they found that "marijuana users define their friendship liaisons in terms of rules and expectations about acquiring marijuana". ${ }^{171}$ Furthermore, marijuana users "built up trusting friendships that can provide them with access to a huge, but hidden and disreputable, marijuana market". ${ }^{172}$ Friendship norms dictated that those in possession of marijuana share, with the expectation that this favour would be returned later. This was the case with Mike who smoked both marijuana and crack cocaine whenever he could access it, but prominently at the end of the month when his cheque came in.

\footnotetext{
${ }^{171}$ Vendula Belackova and Christian Alexander Vaccaro, ““'A Friend With Weed Is a Friend Indeed”: Understanding the Relationship Between Friendship Identity and Market Relations Among Marijuana Users”, Journal of Drug Issues 43:3 2013. At page 307.

${ }^{172}$ Ibid at page 308
} 
Interviewer: How would you describe the people you're using drugs with?

Mike: Alright people.

Interviewer: How well do you know them?

Mike: Friends.

Interviewer: You know them well?

Mike: Couple of months maybe.

Interviewer: What type of relationship would you say you have with them?

Mike: Good one.

Interviewer: Why do you tend to do drugs with those same people all the time?

Mike: I don't really know why I do it, I guess I trust them or whatever, nice people, when they have it they share it with me.

The mutual sharing of drugs helped to sustain and create friendship bonds as well as ensure access to drugs. Foster and Spencer found that drug use is often an interwoven element of friendship. Their research suggests that drug use can: "underlie the intimate moments and feelings of trust that marginalized young people hold dear". ${ }^{173}$ A study of everyday friendship practices, drinking, and pleasure among youths in New Zealand produced similar results. Respondents described drinking alcohol together as a shared experience and routine part of friendship and trust building. Researchers found that respondents found drinking alcohol to be a:

\footnotetext{
${ }^{173}$ Foster and Spencer Supra note 1 at page 229.
} 
"pleasurable friendship practice, smoothing over tensions or negative experiences". ${ }^{174}$ For Brent and Mike, drug use was not the defining feature of friendship but rather the consumption of drugs was a mutual interest that strengthened friendship bonds.

Among respondents who used hard drugs, social interactions were much different. Respondents did not describe the people they used with as friends. This social relationship was created to consume drugs. Respondents described these relationships as solely based on drugs and not genuine friendships.

Interviewer: Who did you usually do drug with?

Rick: The other users.

Interviewer: How did you meet them?

Rick: Blind lead the blind, follow the leader.

Interviewer: How would you describe the people you were using drugs with?

Rick: They say that there your friends but they are not, they say it just to get into your pocket or they are not real friends. They are drug users period.

Rick was not the only respondent to express this sentiment.

Interviewer: How would you describe the people you used to do them with?

Thomas: Some of them were pretty bad.

\footnotetext{
${ }^{174}$ Niland, Patricia et al. ““Everyone can loosen up and get a bit of a buzz on”: Young adults, alcohol and friendship practices", International Journal of Drug Policy 24:6 2013. At page 535.
} 
Interviewer: What do you mean by that?

Thomas: I don't know I guess some of them were all different, some of them steal for their drugs, some of them do this. I don't judge anyone it's just the place I'm at.

Interviewer: What type of relationship did you have with the people you were using with?

Thomas: I guess it's not really a real friendship because it's just over drugs but other than that it's basically just based on drugs

Sam described a similar situation in which drug consumption was the basis of his ongoing relationship.

Interviewer: Now do you usually do it with different people or usually the same girl or same apartment?

Sam: It's usually same person.

Interviewer: What kind of relationship do you have with that person?

Sam: It's just to do with the drug that's it. That's how the relationships are built around the drug kind of thing you know. Not what I want but that's what they want. Kind of thing if it happens it happens.

These narratives demonstrate the more complex role that drug consumption can have in the social relationships of users. Shared drug consumption can be an element of friendship and serve to strengthen bonds of trust and friendship while not being the defining feature of the 
friendship. Or shared drug consumption can serve as the main element of the relationship that is based on users' mutual desire to consume drugs.

Friendship also plays an important role in ensuring access to drugs. Friendship norms may dictate that individuals share drugs with one another when they have them with the expectation that others will return the favour. This helps to ensure consistent access to drugs. In instances where friendships are entirely based on mutual desire to consume drugs, mutual assurance of access to drugs may be the driving force behind these social relations.

\section{Solitary drug use}

Some users of both soft and hard drugs preferred solitary use. These respondents explained that using drugs was an individual rather than a communal experience. For them getting high was not a part of friendship. Guy used to enjoy listening to music when using heroin and did not want to be around other drug users at that time.

Interviewer: Who would you usually use with?

Guy: Myself, you get greedy. I never did like hanging out with other junkies. I used to like listening to music, you just go down right? ... the blues especially.

Interviewer: Was there any reason you did it by yourself all the time?

Guy: I figured if I ever over-dosed I didn't want to be bothered, just like hey they'll find me when they do.

Interviewer: Did you ever have anyone else you used with or always by yourself? 
Guy: Always by myself.

Ryan preferred to smoke marijuana alone because he felt it was peaceful.

Interviewer: Who would you usually use it with?

Ryan: No, I'm a solitary guy.

Interviewer: Was there any reason you always did it by yourself?

Ryan: Well no, no particular reason, more peaceful to be alone than with somebody else.

Jeff preferred to smoke marijuana by himself because he found it easier and enjoyed participating in activities that could be enjoyed when alone.

Interviewer: Who do you usually use with?

Jeff: Mostly by myself.

Interviewer: Is there any reason you usually use by yourself?

Jeff: Not particularly no I just find you know it's easier alone. I mean for the most part I always liked playing video games when I was high, I'm a computer junkie.

Adam, who used to consume cocaine before and during work, had used with other people but he preferred to use when by himself. His preference was to use cocaine and then go work.

Interviewer: You never did it with others? 
Adam: I did it with [people] but people like to go to party clubs, me I'm

different, me I like the quiet, that's it.

These narratives illustrate how user's decisions to consume alone are based more often around personal preference than addiction behaviour. Narcotics Anonymous lists "Do you use alone?" as the first question when trying to determine if a user in an addict. ${ }^{175}$ Contrary to the addiction discourse which suggests that solitary drug use can be a sign of addiction these narratives suggest that solitary drug use may be a matter of personal preference and not inherently a sign of addiction. While I do not wish to challenge the biological definition of addiction, personal preference may also play a role in why some users choose to use alone as opposed to with others or in social settings.

Solitary drug use allows users to escape the social norms and subjectivities associated with drug use. As street involved drug users, they may be stigmatized both as being drug users and being street involved. Solitary drug use allows individuals to define for themselves what their drug consumption means and how it impacts their identity. They can disassociate from drug using subcultures and the identities and subjectivities attached with them.

This may take on additional importance among users seeking to define their own subjectivity. Street involved drug users are marginalized and labeled both as drug users and street involved and solitary drug use may allow them to escape the negative labels such as "junkie".

\footnotetext{
175 “Am I an Addict?" Narcotics Anonymous World Services, Inc, 1988. Available online at $<$ https://www.na.org/admin/include/spaw2/uploads/pdf/litfiles/us_english/IP/EN3107.pdf>
} 


\section{Summary}

Street involved drug users, of soft and hard drugs, regulate themselves and define what constitutes acceptable and unacceptable drugs. These distinctions can include consumption technique, location and drug type. What is considered acceptable or unacceptable varied among respondents. Distinctions were made even among users of hard drugs. While each respondent defined acceptable and unacceptable drug use differently they all based this distinction on avoiding the subjectivity of the "junkie".

The "junkie" label is applied to street involved drug users rather than more affluent, upper class drug users. Street involved drug users are not called "rock stars", or "partiers", their drug consumption is viewed differently. Respondents did not speak of being "rock stars" or "partiers" the way more affluent drug users may be viewed. They did however internalize and reproduced the ideas of what being a "junkie" meant. Respondents had different idea of what it meant to be "junkie" but each understood on their own terms what a "junkie" was. They resisted this subjective position and made rational decisions around their drug consumption that helped them avoid taking on the subjective position of "junkie".

A common view was that intravenous drug use was unacceptable. Within the street involved drug using subculture, intravenous users faced increased marginalization among fellow users. Intravenous drug use was often described as unsanitary and unhealthy. Respondents associated injection drug consumption with being a "junkie". Using needles was often described as unacceptable. Respondents also differentiated between acceptable and unacceptable drug types. Some respondents would only use marijuana, while others were using cocaine or crack cocaine, but not heroin, and one reported using heroin. While respondents had different notions of what was acceptable and unacceptable, almost all had a line they would not cross. Crossing 
this line would have meant a new subjectivity, becoming something else, or moving from being a drug consumer to a "junkie".

Consumption location was important for many respondents. Some were unwilling to use around the shelter, describing it as home and not a location where drug use was acceptable. Among intravenous users there were certain spaces at which they were willing to consume. All intravenous drug users preferred to consume alone and only in specific and familiar locations. These locations served the practical purpose of privacy and safety and allowed individuals to define for themselves what their drug use meant. This allowed them to avoid the "junkie" label and subjectivity associated with intravenous drug use.

Drugs and drug consumption played an important role in friendship among respondents. The degree to which drugs played a role tended to vary between being a mutually enjoyable pastime shared between friends to being the foundation upon which social relationships were built. Friendship norms also helped ensure consistent access to drugs. Contrary to the addiction discourse, drug users who consume on their own may do so because of personal preference and not because of addiction. Solitary use allowed individuals to define what their drug use means to them independent of outside influence. This allowed individuals to define their own subjectivity that may be separate from the drug use subculture subjectivity. 


\section{Chapter 4: Interactions with Police}

In this chapter, the impact of police on the daily lives of street involved drug users will be examined. I will explore how the subjectivity of the "junkie" influences how they are treated by police, how they view police and how they regulate their drug use. As well, the interactions that street involved drug users have with police and how these interactions impact their lives, including strategies to avoid police detection, will be outlined.

I begin by looking at the policing of drugs and drug users as well as how street involved drug users interact with police. I will then move into the regulation of space and how this impacts drug consumption, followed by a look at how individuals work to avoid police when consuming drugs.

\section{Policing of the homeless}

All respondents had experiences with police that ranged from witnessing police interacting with other street involved men to being arrested on multiple occasions. Their perception of police largely depended on their past interactions.

Kevin Walby in his study of National Capital Commission (NCC) Conservation Officers in Ottawa found that NCC Conservation Officers frequently tried to remove or disperse homeless people found occupying certain spaces in Ottawa. These spaces were highly visible and, while accessible to everyone, only some were removed. Walby argues that while NCC officers had the authority to remove anyone: "only unsightly bodies are dispelled from specific spaces, disqualifying them from urban existence". ${ }^{176}$ The bodies dispelled from these areas are:

\footnotetext{
${ }^{176}$ Walby, Kevin, and Randy Lippert, "Spatial Regulation, Dispersal, and the Aesthetics of the City: Conservation Officer Policing of Homeless People in Ottawa, Canada", Antipode 44:3 2011. At page 1028
} 
"frequently visibly stationary, as well as without a home, and therefore, in the words of one NCC officer, not normal". ${ }^{177}$ Street involved drug users are treated similarly by police. They are removed from certain spaces and treated differently in certain spaces. When they are outside of these highly visible spaces, in more socio-economically marginalized areas with higher levels of street involvement, they may be treated more leniently or left alone.

All respondents were living in the shelter and, while none were currently sleeping outdoors, the majority self identified as being homeless. Homeless was the first descriptor many respondents chose to describe themselves. Homeless populations may be marginalized and policed in specific ways to regulate the physical space they occupy. Anti-homeless laws can be used to disperse homeless populations, removing them from certain spaces creating an aesthetic that is ready for capitalist accumulation. ${ }^{178}$ Examples of this can be seen in of laws passed against begging near stores, loitering in parking lots, or in some instances sleeping outdoors. ${ }^{179}$ These laws criminalize actions homeless populations may depends upon, essentially criminalizing survival for the city's homeless. Many of the actions outlawed may be actions that are frequently engaged in by individuals who are not homeless. A charity may ask for money on the street. This is like a homeless person asking for change on the street. ${ }^{180}$ The laws are not aimed at preventing a charity from seeking donations, but rather preventing the homeless from asking for change. Rather than criminalize the action, the law criminalizes the individual. The person is not just homeless but also criminal, furthering the perception that the homeless are

\footnotetext{
177 Ibid at page 1028

${ }^{178}$ Don Mitchell, "The annihilation of space by law: the roots and implications of anti-homeless laws in the United States”, Antipode 39:3 1997. At page 307.

${ }^{179}$ Ibid at page 307.

${ }^{180}$ Ibid at page 311
} 
undesirable. These external factors may impact the individual's subjectivity, furthering the narrative that the homeless are unwanted, or obtrusive. A frequent justification for laws that target homeless populations is that they may threaten public safety by attracting increased drug consumption and sales, public intoxication or a range of other safety risks. ${ }^{181}$ This further socializes people to view the homeless as criminals and undesirable. Police officers often view themselves as crime fighters and want to be viewed as such. ${ }^{182}$ Police officers are tasked with policing a homeless person who is depicted as foreign, undesirable and criminal. This may form the basis of a relationship between police, who view themselves as crime fighters and homeless populations who are often viewed as criminal.

In Ottawa, there are no laws that directly target the means of survival of homeless populations. While the homeless person may not be criminalized they are depicted as foreign and intrusive to capitalist accumulation and consumption within certain spaces. Police regulate what space homeless people can occupy and push them in and out of certain spaces. Recent studies suggest that police may do so to limit homeless persons to areas with a high level of support services to encourage them to seek help. ${ }^{183}$ By making certain areas uncomfortable for homeless persons, police hope to encourage these individuals to re-evaluate their aversion to social services and assistance. ${ }^{184}$ This goal fits within the neoliberal framework of creating the self regulating capitalist individual. The undesirable population, in this instance the homeless, needs

\footnotetext{
${ }^{181}$ Ibid at page 308-309

${ }^{182}$ Lori Beth Way, and Ryan Patten, Hunting For “Dirtbags”, (Boston: Northeastern University Press, 2013). At page 2 .

${ }^{183}$ Forrest Stuart, “On the Streets, Under Arrest: Policing Homelessness in the 21 st Century”, Sociology Compass 9:11 2015. At para 14

${ }^{184}$ Ibid at para 14
} 
to be helped or fixed and certain undesirable subjectivities need to be corrected or eliminated so that they no longer disturb regular productive capitalist activity within the neoliberal framework.

Intensification of law enforcement has been a primary response to concerns regarding drug use, especially street level drug use. The intensification of law enforcement is usually aimed at reducing both the use of drugs and the supply of drugs. ${ }^{185}$ There are a variety of strategies available to law enforcement when attempting to crack down on illegal drug use. Sweeps can increase the number of officers in a specific area for an extended period, or increasing police surveillance and presence in an area for a short period. Sweeps may also involve undercover police work where an officer may pose as either a drug buyer or seller. ${ }^{186}$ Attempts to control street level drug use can also involve traditional policing tactics such as, stop and search, street level chases and physical restraint. ${ }^{187}$ While these methods have been the traditional approaches to reducing drug use, the actual effectiveness has more recently come under heavy scrutiny.

Respondents were familiar with these methods of policing and controlling street level drug use. They were aware of police sweeps in Ottawa, with stop and search and physical restraint tactics. Some respondents had been involved in physical altercations with police and others had been stopped. They were always prepared for the possibility of contact with police.

\section{Interactions with police and view of police}

Every respondent had experiences interacting with police. These experiences varied as did their perceptions of police. Some respondents had negative interactions while others spoke

\footnotetext{
185 Thomas Kerr, et al., "The public health and social impacts of drug market enforcement: A review of the evidence”, International Journal of Drug Policy 16 2005. At page 210.

${ }^{186} \mathrm{Ibid}$. at page 211

${ }^{187} \mathrm{Ibid}$. at page 2011
} 
positively regarding their interaction. Respondent's perception of police was formed by how they viewed these interactions.

Following interactions with the police, Warren and Sam, followed similar strategies to avoid further interactions but had different views of police. Warren spoke negatively about the Montreal police and drew attention to the scar on his nose which he credits the Montreal police.

Interviewer: How did they treat you when they picked you up?

Warren: Typical Montreal cops, grab you, slam you up against the car, give you a shot in the kidneys, knock your head off the roof.

Interviewer: How often did they find you when you were on drugs?

Warren: At least once a week.

Interviewer: Was it usually the same type of treatment?

Warren: Oh yah, it was always the same treatment, compliments of Montreal cops. [pointing to a scare on his nose]

Sam on the other hand did not speak negatively about police or his encounter. While he did adjust his behaviour following his encounter he did not report a negative impression of police.

The views of many respondents were determined by their interactions with police. John reported a negative experience with police in Ottawa in which they did not seem concerned when he was beaten up, and he credits this to his past criminal record.

John: The Ottawa Police are shit man, they really are. I got attacked, I got beaten down, I ended up going to the Civic Hospital, that Salvation Army van 
brought me there. I was covered in blood, this entire side of my face, it's been five months later, my back has been out. But you know what I went to the station the day after the attack because the investigator called here and left a message, so I go to the police station and I get the pictures taken, you know I talk about it a little bit, I wasn't there to make a statement so I didn't write anything down. But there was one last thing that he wanted to do so he gives me a business card or something but he was gone for a few minutes in the back of the police station. I was on Elgin Street, he was gone a few minutes I'm standing there I'm waiting, I'm waiting, I'm wondering what's taking him so long. Well when he came out the look on his face had totally changed. Totally changed you know why, because he looked me up. I was no longer a victim anymore. Now I was a guy who had a record that got beaten in front of a shelter, changes everything. My drug use has changed according to the police and however they think of people when they get phone calls and stuff. I still have problems with the guy that was doing that too me. I called, I contacted the police three times to get blown off. Now that I have a record I can't even count on the police to help me in a time where I need help. I'm basically on my own because I'm one of them now, that's how I see it.

John had a negative experience with police and felt they failed to help him or treat his case seriously. As a result. he has a negative view of police, describing them as 'shit'. He felt the police treated him differently once they learned he had a record. He was no longer viewed as a victim of a crime but rather as a street involved individual who had been involved in an altercation. The police no longer believed he was capable of the victim subjectivity, instead he 
was defined by homelessness and past criminal activity. Like John, Mike also felt mistreated by police, that they unfairly targeted him because of his son, who was also a user.

Interviewer: How have the police treated you?

Mike: Badly, because of my son they treat me you know differently. Brock, he's a bad boy, but you know they are taking it out on me. Cause I'm the father but it seems like what I tell him to do he don't do it so I get the shit end of the stick.

In an earlier interview Brent described a situation in which he felt that police in Ottawa treated Mike unfairly.

Brent: Just like a couple weeks ago three police officers physically telling [Mike] that's in my room, calling him a bad dad. That you are a stupid cock sucker you know, it's just like you are not supposed to talk to people like that, you know it doesn't matter the situation.

Brent also felt that police in Ottawa treated drug users, and street involved people, harshly at times.

Interviewer: How do you get treated by the police?

Brent: Being homeless or in general?

Interviewer: In general.

Brent: Depending on the situation, not too bad. Sometimes it's like anything else they've got a job to do which is very stressful. So most of the time it's 
pretty good, sometimes they get to be a little rougher around the edges than they should be really. Authority figure of course but there's such a way as talking to somebody as well.

Brent felt attacked at times near the shelters, and that police treat street involved or homeless people differently than others.

Interviewer: Are there certain places in the city the police treat you differently than others?

Brent: I've heard around the three missions that are around here that they know you're homeless and they do treat you like a piece of shit the way they talk to you and stuff like that. I've felt myself attacked a few times, it's not my fault I'm here you know but they look at it you're homeless you are just a piece of shit so they can treat you or talk to you anyway they want which isn't right.

Brent's experience being treated differently around the shelter than in other areas of the city may be an example of police regulating certain spaces differently to encourage enrollment in social services. Homeless is an undesirable identity, one that needs to be "fixed" or "rehabilitated". Brent speaks about being treated differently because he is homeless. Brent's subjectivity as a homeless man allows for him to be treated differently, especially when in space frequently occupied by homeless people.

Thomas felt unfairly targeted by police because he was known for selling drugs. He reported to being frequently stopped by police.

Interviewer: And how do they [police] treat you? 
Thomas: Uh, I guess they treat me, they treat me unfair really.

Interviewer: What do you mean by that?

Thomas: Well since I'm known as a drug dealer they search me all the time and harass me.

Thomas felt harassed by police and had negative interactions with police in Ottawa. He felt that his identity as a drug dealer causes police to treat him differently. He is defined and identified by his drug use and drug dealing and his presence in commercial spaces may be viewed as an interference with regular capitalist economic activity.

Other respondents reported having positive interactions with police. Some respondents were treated kindly and felt that police were always kind to them if they were respectful to the officer. Rick reported that he never had a problem with police. While he had been caught by police, he maintained that they never caused him any problems. They treated him fairly, and in accordance with procedural justice and proper process.

Rick: I never had a problem with the police, when I did I don't give them a hard time that's what they're there for. Whether they are on the dole or not, they are there to help, mostly women and children.

Interviewer: How did they treat you when you got caught?

Rick: I've never had a problem.

Similarly, Ben reported that he was treated well by police and that he never experienced problems in his frequent interactions. 
Interviewer: Did you have any interactions with police in Ottawa or in

London?

Ben: Yah there's lots of interaction with them.

Interviewer: How did they treat you?

Ben: Fairly well to be honest seemed that if I gave them respect most of them would show me respect.

Ryan used to inject cocaine everyday before he was caught by police. He spoke positively and credits them with preventing him from going further into drug abuse.

Interviewer: Did the police have any impact on how you would get drugs or use drugs?

Ryan: Yah probably.

Interviewer: How so?

Ryan: They stop me doing it, I did some crime and I been caught so because of that I didn't went further into drug abuse.

Interviewer: Was it drug crime you were stopped for or something else?

Ryan: What do you mean?

Interviewer: You said the police stopped you for a crime.

Ryan: Yah but because of that I was unable to live like this anymore, so I was arrested, did some time because of that. I maybe save my life. 
Interviewer: How did the police treat you when they stopped you?

Ryan: Kindly.

Ryan still smokes marijuana and tries to avoid carrying enough to get charged. He spoke positively about police. His interactions with them did not vary based on use of hard or soft drugs.

There was no predictable pattern of positive or negative interactions with police based on using hard or soft drugs. What appeared most consistent was the unpredictability of both the interactions and how it was perceived. This suggests that interactions between users and police are highly variable, depending on the user and the involved police officers.

\section{Regulation of homeless space}

Some respondents reported different treatment by police in different places. In Forrest Stuart's Ethnographic Study of Police Patrols in Los Angeles' Skid Row, it was found that within Skid Row police treated the homeless differently than they did in other areas of the city. Rather than remove homeless bodies from this space, police would try to modify behaviour within the space by trying to curtail certain activities and encourage homeless individuals to seek recovery and social services. ${ }^{188}$ This was contrary to how police dealt with homeless bodies in other spaces in which they were frequently removed. ${ }^{189}$ Within productive capitalist spaces homeless bodies may be out of place and be removed. Within unproductive less affluent spaces, homeless people are allowed and may access services to fix their deviant behaviour.

\footnotetext{
${ }^{188}$ Forrest Stuart, "From 'Rabble Management' to 'Recovery Management': Policing Homelessness in Marginal Urban Space", Urban Studies 51:9 2014. At page 1921.

${ }^{189}$ Ibid at page 1921
} 
Thomas reported that he was treated differently in Vanier than in other Ottawa neighbourhoods. Vanier is close to downtown Ottawa and perceived by many to be socioeconomically marginalized with more street level crime.

Interviewer: Are there any places in the city they treat you differently than others?

Thomas: Downtown's a lot more strict, like I originally started in Vanier and it's a lot more different. There the police are a little more lenient than here.

Interviewer: How so?

Thomas: There you can I don't know, downtown they're stricter because it's more public people down here and there it's just they're used to it there.

Interviewer: So, in Vanier you can get away with it a bit easier?

Thomas: Yah.

Thomas reported that police were less tolerant in downtown Ottawa. In Vanier, police were more lenient towards street level drug use. Vanier is generally perceived as being more socioeconomically marginalized than downtown Ottawa with higher levels of street crime. As such, Thomas is treated differently in Vanier than in downtown Ottawa.

Guy had consumed drugs in several cities and had experience with different police forces across Canada. Like Thomas, he was treated differently depending on the socio-economic condition of the area in which he was consuming drugs. Guy was treated better by police in Vancouver than in North Bay or Toronto. When Guy was in Vancouver he was using drugs in the downtown east side, an area known for high rates of street level drug use.

Interviewer: Did the police have any impact on where you would use? 
Guy: Oh yah, especially in Vancouver they would always. But you know what they weren't that bad actually, They'd help you if you were fucked up but they were always around.

Interviewer: How did they treat you?

Guy: If you got to know them they'd treat you alright, you know you didn't want to fuck with them because they'd tune you up but other than that, you know, live and let live.

Interviewer: Were there any places that the police treated you differently than in others?

Guy: Yah Toronto, Toronto's a bad place oh yah. The cops there were pretty bad, North Bay uh North Bay is a lot of Toronto cops who can't make it in Toronto get sent to North Bay so they're not very good. A few other places. But on the most part you know if you're not acting like a fool and bothering anybody, senior citizens especially, you're not trespassing onto somebody's property, they leave you alone, and you know you don't do it (drugs) right out in the open.

Guy's experience is like Thomas'. Police in Vancouver's downtown east side, a socioeconomically marginalized area known to have high rates of street level drug use, were more tolerant, lenient and at times, helpful to users. In Toronto and North Bay, not as frequently associated with such concentration of street level drug use, police were less tolerant and lenient towards users. 
Warren reported that when he was using in Montreal there were certain areas of the city that drug users tended to occupy. He would avoid these areas because he was concerned that would increase his chances of being picked up in a police sweep of the area.

Interviewer: Were there certain places in the city you found they treated you differently than others?

Warren: Yah down around Point St Charles area and that the cops were not so bad but in the downtown area of Montreal you watched what you did, hardcore cause they were known to be assholes around there.

Interviewer: Did you sort of go into different places to avoid them?

Warren: Oh yah, after a while I just stopped going through downtown Montreal I'd go out to Verdun, go out to the West Island.

Like Guy and Thomas, Warren's response illustrates how there are geographic areas in which drug users are treated differently. In Warren's case, this was outside of the downtown core, in more secluded less public areas.

Like Warren, Jeff reported that he predominantly used in the outlying areas of Ottawa. Jeff found that police left him alone when using outside of the downtown area.

Interviewer: Did the police have any impact on how you would look for or get or use?

Jeff: Not really, I mean in the 20 years that I've been smoking drugs I've never been arrested for pot or even been pulled over, nothing. The outlying areas, in this area you get left alone pretty much I mean the pot scene is, it's quiet, they 
don't seem to really care about marijuana. It's only down here where you seem

to find that there's lots of drug dealers and there's lots of people selling all

kinds of different drugs. So anyhow, down here you'd see that more often. You

have to be like looking over your shoulder I guess.

When drugs are consumed in areas that are associated with higher levels of drug consumptions such as Vancouver's downtown east side or Vanier, police are more lenient. When drugs are consumed in the outlying areas of the city, users may be less likely to encounter police than in the downtown areas of the city. This was the case for both Warren who used in Montreal and Jeff who used in Ottawa. This suggests that there are certain areas that drug consumption is tolerated more than others by police. What these areas have in common are that they are out of view of the public. ${ }^{190}$ They are not areas in which a user's drug consumption is likely to be encountered by non-drug users. The areas are either secluded and private or in socioeconomically marginalized areas.

\section{Routinization of avoiding police and group strategies of avoiding police when using drugs}

All respondents sought to avoid police regardless of whether they viewed them positively or negatively. Even if users were not concerned about police catching them while using drugs, they still avoided police. Routinization can occur in response to a similar set of events occurring in a similar fashion and producing similar results. In a study of investigators dealing with criminal cases, it was found that certain pieces of routine information would be sought out to 
help determine if a case was routine or not. ${ }^{191}$ Past experiences with cases allowed investigators to make determinations about what was routine. The designation of routine cases was based on experiences of investigators. The illegal nature of drug use and potential criminal consequences can cause users to actively avoid police detection. Users develop strategies to avoid police. These strategies can become a routine part of daily life for drug users.

Reliance on fellow street involved users was common among respondents who used in groups. Respondents who used hard drugs were particularly careful about who they trusted. Concerns about police detections and intervention were a common concern for hard drug users and a significant factor to determine who they could trust.

Thomas was the only respondent who had been a drug dealer. He had been convicted of trafficking and had recently been released from prison. He knew the strategies Ottawa police used for drug enforcement and had his own tactics to avoid detection. Thomas was increasingly careful about to whom he would sell drugs to avoid undercover police.

Interviewer: Is there any experience you've had with police at that area?

Thomas: I had an undercover that was pretending he was a junkie and he was coming in and out. One of my friends got busted by him. I told him not to sell to him because we didn't know him and then he got caught for trafficking because of that.

Interviewer: How well do you usually know the people buying from you?

\footnotetext{
${ }^{191}$ Waegel, William B., "Case Routinization in Investigative Police Work", Social Problems 28:3 1981. At page
} 273. 
Thomas: Uh I know them, I just know them. If they're a user then I'll sell to them, if not, if I don't know that they're like using it or if they look like they clean things like that I wouldn't sell it to them

Interviewer: You said your friend got busted by the undercover, the cop, you didn't know the guy at all?

Thomas: No, he was coming for like two weeks and always went to him.

Thomas did not want to sell to unknown buyers. He would screen potential buyers who he thought could be undercover police. He was not only aware of strategies Ottawa police use to crack down on street level drug dealers and users but had adapted his behaviour in accordance.

For Thomas, trust was the major factor in deciding to whom he would sell drugs. This is like the findings of Matthew Taylor and Gary R. Potter who looked at the relationships between lower level dealers and customers in England. They found that in lower lever drug deals: "friendship and trust remain key to relationships with suppliers and customers". ${ }^{192}$ While Thomas didn't classify his customers as friends he emphasized the importance of trust. $\mathrm{He}$ mentions the importance of knowing who consumes the drugs and only selling to them to avoid police. Police play a key role in social relations of street involved drug users. Trust plays a major role in their friendships and social relationships. Thomas adapted his behaviour to avoid detection and to minimize criminal charges in the event he was caught. Thomas described operating as part of a team in which one person would watch for police, one would hold the

192 Taylor, Matthew, and Gary R. Potter, "From "Social Supply” to "Real Dealing”", Journal of Drug Issues 43:3 2013. At page 393 
drugs and the other the cash. The goal of this system was to both avoid police detection and receive a lesser charge in the event of arrested.

Interviewer: Do you know if anyone else is being more careful now?

Thomas: A lot of people are being a lot more careful instead of one guy holding it all they'll have like three guys. One guy holds the money, one guy holds the drugs, one guy watches for the police

Interviewer: When you go indoors to sell do you have anyone else with you?

Thomas: I always have a person with me just in case.

Interviewer: Is it the owner or somebody else?

Thomas: One of my good friends.

Interviewer: What's their role?

Thomas: Just to watch for police, things like that if someone messes around he does something.

Interviewer: So you'll have one person on the lookout one person handling things?

Thomas: Yah.

Interviewer: Is it always just two people or do you usually bring someone else?

Thomas: Sometimes it's more than that, sometimes it's a group of people.

Interviewer: Do you always have equal jobs? 
Thomas: Yep normally there's a guy that holds the drugs, one guy holds the cash cause then if you get busted you don't get busted for trafficking you just get possession.

Interviewer: And one person is always on lookout?

Thomas: Yah.

Interviewer: Is everyone who is selling in Ottawa using that kind of strategy now?

Thomas: A lot of people do especially on the streets now there's always like a, there's always partners.

Thomas was aware of both police strategies to detect street level drug dealers and users but also aware of the potential legal charged he could face if caught. Thomas adapted his behaviour and developed new strategies to avoid police. These strategies, namely selling with partners and only to people he trusted, became routine elements of selling drugs.

Adapting behaviour and developing new strategies to avoid police was common among respondents interviewed. Other street involved drug users developed ways of monitoring and guarding against police intervention.

Interviewer: Do adjust what you're doing at all to avoid the police?

Mike: No, just be careful.

Interviewer: The people you're with, do you guys keep an eye out for police at all? 
Mike: Yah, six up.

Interviewer: Six up?

Mike: Yah, if a cop goes by or whatever, six up and it means there's a cop around.

Interviewer: What's the six up mean?

Mike: Watch there's a cop.

Interviewer: So somebody just says six up and everyone knows there's a cop?

Mike: Yah.

Interviewer: And you just change what you're doing.

Mike: Yah, act normal.

Interviewer: Six up, is that just with people you know?

Mike: No, mostly all the druggies use that.

Interviewer: You just yell six up and everybody knows?

Mike: Yah, and be ready to hide your stuff.

Interviewer: How often does that happen where somebody yells six up?

Mike: Every time a cop goes by.

Interviewer: Where did that come from the six up? 
Mike: I don't know, but I start, I said what the hell's that, a cop? Every time I

see a cop six up, if I'm rolling a joint, put it down.

Mike illustrates how street level drug users work together to avoid police, and how this subculture has created a code to alert each other when police are present. Despite not knowing where the term "six up" originates, Mike uses it and understands its meaning within the street involved drug user subculture. This term and the reliance on fellow users was a routine part of avoiding police.

Both Mike and Thomas show how street level drug users and sellers work to avoid police detection and police interference. The trust between users and between sellers and users was extremely important. Both were careful or in Thomas' case, careful and cautious about who he sold to. He would not sell to people he did not know or trust. They also discussed the important role that other street involved users and sellers played in helping to avoid police. A 1991 study by Denise Kandel and Mark Davies found that among individuals who consume drugs, especially drugs other than marijuana, close friendships tended to be more intimate. As well, individuals doing illegal drugs other than marijuana, were more likely to choose friends that used similar drugs. ${ }^{193}$ Both Mike and Thomas consumed with those who used similar drugs and described bonds of friendship with these individuals.

Thomas also spoke about only selling to friends or people he knew. The friendship between dealer and purchaser can be important especially as it pertains to suppliers who sell only to their friends. These "social suppliers" are closely linked to their customers and usually sell

\footnotetext{
${ }^{193}$ Denise Kandel and Mark Davies, "FRIENDSHIP NETWORKS, INTIMACY, AND ILLICIT DRUG USE IN YOUNG ADULTHOOD: A COMPARISON OF TWO COMPETING THEORIES”, Criminology 29:3 1991. At page 459 .
} 
what are considered softer drugs such as marijuana. ${ }^{194}$ Although Thomas was selling drugs that are harder than marijuana, he maintained many of the same values associated with social supplier drug dealers, specifically he would only sell to friends. The reliance on fellow users to help avoid police was common among respondents who reported using with others. Scott relied on the people he was using with to help avoid police and they would work together to decrease the likelihood of detection.

Interviewer: Did the police ever catch you?

Scott: No.

Interviewer: When you were doing it with a group of people, did you have any ways to make sure someone looked out for the police?

Scott: Always, there's always one-person lookout, I mean you don't want to get caught right so there's always one set of eyes looking around for something.

Interviewer: Was it always one person and that's whose job it was?

Scott: Sure, it is until it's his turn or whatever to get his high or fix or whatever you want to call it, and then somebody else would take a lookout

Interviewer: Was the person on lookout high at all?

Scott: No, unless you got to the end. He was always the last guy to do it right, that's why you did it. The first guy to get high he waited until the end, then he

${ }^{194}$ Supra note 181 at page 404 
would look out. So, if it was a bad batch, fix, whatever you want to call it, then you would be whoa, you didn't want that guy out there looking.

Like Mike and Thomas, Scott trusted those he used with. For all three, the ability to trust fellow users or in Thomas' case, buyers, was an important part of avoiding police. Scott went further in explaining how he would only use drugs with people who could be trusted to help avoid police.

Interviewer: How good a relationship did you have with the people you were using with?

Scott: They're friends.

Interviewer: Was there a reason you usually did it with those people?

Scott: Well you trust them, you don't want somebody running to the cops going hey look this guy's selling drugs or he's picking them up or asking me if I wanted to buy stuff.

Scott's response illustrates how trust is a major component of friendships among street involved drug users. Police have an impact on the ability to establish this trust. Scott did not want to use drugs with people he could not trust. For Scott, avoiding police played a role in how he established trust and friendship with other users.

This builds on the findings of Matthew Taylor and Gary R. Potter. Trust and in some instances friendship is important among street involved drug users and sellers and extends beyond the buyer - seller relationship. Trust and friendship can also play an important role in how street involved hard drug users work together to avoid police detection. In some instances, 
avoiding police can play an important role in the establishment of this trust and friendship among street level users of hard drugs.

\section{Avoiding police when using outdoors}

Some respondents used drugs when they were alone. These respondents did not rely on or trust friendship groups to help them avoid police. This meant they used different strategies to avoid police detection. Difference strategies were used indoors and outdoors. Outdoor users were often more cautious about where they would use drugs whereas indoor users were cautious not to draw attention when using.

These individuals did not have their own space in which they could consume drugs, and had to adapt and fit into spaces not designed for them. The consumption of drugs in these spaces could be viewed as an act of resistance to dominant norms and society. Michel de Certeau theorized that: "a way of using imposed systems constitutes the resistance to the historical law of a state of affairs and its dogmatic legitimation". ${ }^{195}$ People must maneuver and reconstitute space as their own. Or as de Certeau wrote: "since they lack their own space, they have to get along in a network of already established forces and representations". ${ }^{196}$ They must adapt and work around existing rules that constrain certain spaces. Outdoor spaces are not designed for drug consumption. This means that those consuming drugs in these spaces must work around the existing rules to reconstitute these spaces as their own.

Guy used multiple locations to inject drugs. This helped prevent other users from using his hiding sports but also helped him evade police detection when using outdoors. John reported

\footnotetext{
${ }^{195}$ Michel de Certeau, The Practice of Everyday Life, Volume 1. (University of California Press. Los Angeles, California. 2011) at page 18

${ }^{196}$ Ibid at page 18 .
} 
that he only smoked marijuana and would no longer use hard drugs. He preferred to smoke alone. Unlike Guy, who was using hard drugs, John stuck to marijuana.

Interviewer: Well, do you have any ways to make sure they don't catch you?

Do you have any strategies you use to make sure they don't catch you when you're using or buying?

John: I usually try and find a hiding spot, I'm not one to go and sit out in the open too often. I avoid police. I don't see a car from across the street and then book it the other way, but if I see I'm going to be passing by a few police officers I know I'm a kind of red eyed, I might smell a little bit like weed, well I'll just casually walk on over. See, I got caught smoking pot once by two police officers, that ended up being a bit of a problem. Aside from that, I'm discreet, I don't make a big deal out of it, I try to find a place to go that's out of the way. I don't know there's not much else to tell.

Interviewer: Is it usually the same spots you use all the time?

John: Same general areas, like a city park once the sun goes down. But I don't sit at the same bench all the time, I find a dark spot somewhere in the city where you're not going to be too visible and just, you know, smoking pot isn't like sitting down with a case of beer. You don't need to be there for like 20 minutes, half an hour usually. Nice quick little fix and then off to do other stuff.

Despite the difference in the drugs consumed John and Guy employed similar strategies to avoid police. 
Respondents who consumed outdoors as part of a group also sought to find a hiding spot when consuming. Scott found places that were hidden or out of sight to consume drugs when he was using.

Interviewer: Did you have any ways to make sure you never got caught?

Scott: Sure you, you don't do it in the open, a lot of seedy places like alleys, dark alleys and shit like that but you always find that if you are that addicted you always find a way to do it or where to do it, you know, I mean if you are smart about it. Some of these people they just don't give a shit, they'll do it anywhere and everywhere.

Despite usually using with a group, Scott still used many of the same techniques as John and Guy who used alone. The desire to find a secluded space to consume drugs applies to both users who consume in a group and who consume alone. In some instances, this applies to users of hard and soft drugs.

This adds to the findings of the previous chapter. Hard drug users who consumed outdoors frequently sought a safe place to consume drugs. The space was deemed safe based on its ability to shield users from police. This illustrates how the avoidance of police can become so ingrained and routinized among users that it can impact who users form friendships with.

\section{Avoiding police when using indoors}

Respondents who used indoors also wanted to avoid police intervention when consuming drugs. These respondents had a physical barrier between them and the public when using however, they still reported strategies to avoid police interference. Sam preferred to use alone but 
would use with others if he could access indoor spaces. He tried to avoid interactions with police in general and when consuming drugs he attempted to be as inconspicuous as possible.

Interviewer: Do the police have any impact on how you would get or use drugs?

Sam: No not really. I stay away from police. I don't want to have any involvement.

Interviewer: Do you have any strategies to avoid them?

Sam: Don't be conspicuous, just be normal, just act normal, everything's fine, you go right by you know. Is that what you mean?

Interviewer: Yah.

Sam: I just don't bring attention to myself you know. If they go this way I go the other way, try to stay away from any confrontation with them.

Beyond trying to avoid confrontation with police, Sam tried to ensure they would not intervene when he was using indoors. Sam did not have his own space and would use a friend's apartment, or occasionally a hotel room.

Interviewer: And when you're with somebody do you guys have any strategies to make sure police don't catch you using it?

Sam: Well we don't bring attention to ourselves, we don't, we're not loud, we're not rambunctious, there's no fighting, you know what I'm saying, no reason for the police to show up 
While Sam had the physical space between himself and police, unlike outdoor users, he still wanted to ensure he did not draw their attention. Like respondents who consumed outdoors, Sam wanted to avoid interaction with police when using. While he did not have to hide like outdoor users, he still wanted to avoid attention and be as discreet as possible.

Warren only used indoors like Sam, but he always used alone. Warren had his own home and his own space in which to consume drugs. As a result, he was not concerned with police intervention when he was consuming or buying drugs. Although he had been picked up by police when he was high on drugs, he had never been caught using or buying.

Interviewer: Were you using indoors or outdoors?

Warren: Indoors, I always shot up at home. I didn't feel safe doing in anywhere else.

Interviewer: Did they [police] change at all how you got the drugs?

Warren: Nope, because like I said I'd just call my buddy and he'd bring over whatever I wanted, whatever I needed.

Interviewer: And what do you think the police thought of you when they picked you up?

Warren: Oh at that point in time I don't think I cared back then. Now I look back on it and think dumbass cause a lot of these guys knew my dad.

Interviewer: Did getting caught change the way you would buy them or use them at all? 
Warren: No, like I said I was always using at home, I never had stuff on me and I had it brought to me so I never had stuff on me whenever I was out.

Despite not being concerned with police intervention when buying or using, Warren was concerned about police intervention when in public and around other users. As a result, he developed strategies to avoid police when in public regardless of whether he was using or in possession of drugs at the time. The avoidance of police became a routinized part of his life. Over time he developed what he described as: "an ability to sense police presence". He memorized the make and model of vehicles frequently used by undercover police, as well as common physical traits of police officers and the plate number of police vehicles.

Interviewer: When you were paranoid were you better at detecting the cops or did it make it harder?

Warren: I was pretty good at picking them out pretty much all the time but when I was paranoid I seemed to be more sensitive, I think it was because I was so paranoid.

Interviewer: Can you still detect cops?

Warren: Oh hell I can walk down the street and go that's a cop, that's a cop car, that's a cop car down the street. The thing is that the cops aren't real smart with their choice of cars, once you get used to what they are driving it doesn't take long to spot them.

Interviewer: Did you get good at detecting even stuff like that when you were using? 
Warren: It depends, after a while you get used to seeing certain types of cars but if they throw a new one in the mix that kind of throws you, and it throws you until you get used to it. And there's certain characteristics of the car. That one's got a scratch in the back fender or uh its got a tail light that's cracked, stuff like that you can spot, or its got a crack in the windshield, its this colour, its got that markings on it, certain things you pick out.

Interviewer: Was it usually the same cop cars that would have the same markings?

Warren: Oh yah, usually they use the same cars for about two to three years, then they change them up and you got to get used to whatever the new ones are.

Interviewer: And you memorized the traits in each car?

Warren: Oh yah, pretty much. You could walk down the street and go cop car especially in Montreal because they would use anything they picked up in a drug raid or whatever and after awhile you get used to seeing certain cars in certain areas and the same people driving the cars. And you can spot a cop from a mile away just by the way his hair is cut and everything else, at least you used to be able to, now not so much because now they're allowed goatees and stuff like that, they're a little harder to spot sometimes.

Interviewer: So, you'd have the cars memorized and everything they would be in? 
Warren: Oh yah, I could probably tell you back then the licence plate numbers on some of them.

Interviewer: You had it memorized even the plate numbers?

Warren: Yep, when you get that paranoid you pick up stuff.

Interviewer: You had it memorized or written down?

Warren: Memorized, my memory used to be good, it's not so good anymore.

The illegal nature of drug use and potential criminal consequences means that users must avoid the police. Users develop avoidance strategies which become routine behaviour. Warren's routine involved memorizing the details of police vehicles and going out of his way to avoid any interactions. Ritual can challenge both the normal moral order and prevailing social norms. ${ }^{197} \mathrm{By}$ avoiding police, he resisted the moral and legal order that police represent, as well as the social norms that discourage drug consumption.

Using indoors in his own home and avoiding police allowed Warren to define for himself the meaning of his drug use. Rather than being defined by the identities of other drug users or by the legal consequences if caught by police, Warren determined his own identity and subjectivity. He could avoid the subjective label of criminal, or "junkie".

There were also practical reasons for Warren to avoid the police. He reported being roughed up and having his nose broken during one interaction with Montreal police.

\footnotetext{
${ }^{197}$ Jacqueline Cossentino, "Ritualizing Expertise: A Non-Montessorian View of the Montessori Method", American Journal of Education, 111:2, 2005. At page 214.
} 
Warren: Oh yah, it was always the same treatment, compliments of Montreal cops.

Interviewer: What happened?

Warren: Got my nose busted about four times by them, smashed my face into the side of a cop car.

Like Warren, Sam's desire to avoid police and always use indoors, was based on his previous experience.

Interviewer: Have you had any interactions with the police related to drugs?

Sam: When I was in Mississauga I had interactions. They came, they said wait a bit more, I brushed it off and nothing happened at that time but you know still they were there.

Interviewer: Did that interaction change at all how you tried to avoid them?

Sam: In the aspect, I don't want to have any police so I don't go in the public, cause before I was in the public type thing in the park and this way I don't do that anymore. So, it did alter my way, yes.

Interviewer: So, you do it more indoors now?

Sam: I do it more privately.

Both Warren and Sam routinely avoided police. For both this routinization of behaviour was based on past experiences. Sam also altered where he would use drugs. The desire to avoid police can change the behaviour of drug users, and this new behavior can become routine. This 
demonstrates that routinization of police avoiding is not random but rather a response to previous experiences.

Warren and Sam make particularly interesting case studies as both use indoors. Their efforts to avoid police despite neither being overly concerned with police intervention while using or buying, demonstrates how ingrained this can become. It also demonstrates that both those who use indoors and outdoors avoid police.

These two examples illustrate how vastly different interactions can routinize similar behaviours. The interaction Sam described did not result in an arrest and could be considered relatively minor. The interactions Warren described were more severe, resulting in a broken nose and as he described: "having his face smashed into the side of a cop car" on multiple occasions. This was a more severe interaction than Sam's. Despite this difference both avoided police after the incidents and developing ongoing avoidance strategies as a result. This suggests that interaction with police of any type may motivate users to develop avoidance strategies.

\section{Consistent themes with police and street involved drug users}

The interaction between street involved users and police varied. It was difficult to pinpoint a specific pattern that this interaction followed as some respondents reported positive and others reported negative interactions. Despite the differences, almost all respondents used a range of strategies to avoid police detection when using drugs. These strategies and behaviours often became a routine part of their daily life. The desire to avoid police was common regardless of respondent's positive or negative views of police.

Users were most heavily policed in areas of capitalist consumption, near stores and downtown. In areas with lower socio-economic status or secluded areas, users seemed less 
concerned and less likely to interact with police when consuming drugs. In areas of lower socioeconomic status and perceived as having a higher rates of street level drug use and crime police appeared more lenient towards drug consumption. 


\section{Chapter 5: Conclusion}

Street involved drug users have defined acceptable and unacceptable drug use for themselves. Distinctions are based on the type of drug and method of consumption. Users differentiated between what they considered hard drugs such as heroin, crack cocaine and soft drugs such as marijuana. They also drew distinctions between use of intravenous and nonintravenous drugs. Some were willing to use marijuana but would not use hard drugs. Others were willing to use some hard drugs such as cocaine and crack but not heroin. Even for some intravenous drug users, heroin was considered unacceptable.

Street involved drug users do not want to be labeled a "junkie" based on the stigmatization of a "junkie". Each respondent had a slightly different definition of acceptable drug use. However, all viewed drug consumption that fit into the broader narrative of everyday life as acceptable and drug consumption that became the defining feature of life as unacceptable. The latter behaviour defined a "junkie" and respondents found ways to avoid this subjective position.

Among respondents there were varied definitions of acceptable drug consumption versus becoming a "junkie". For some respondents, use of marijuana was acceptable but consuming other drugs was unacceptable as it took on the subjectivity of the "junkie". Other respondents refused to use needles. For them, the consumption of various drugs without the use of needles was acceptable but needles were reserved for a "junkie" and as a result, they avoided any drug consumption involving needles. Among respondents who did use needles, they often chose to be alone when using drugs so that they could define the meaning of their drug consumption and avoid the subjective position of "junkie". 
The consumption of drugs was a major factor in the formation of social groupings. Obtaining and consuming drugs had significant impact on how some respondents formed friendships. A shared desire to obtain and consume drugs often formed the basis of friendships and social relationships. In some instances, social relationships formed almost entirely to access drugs rather than a genuine friendship. Among other users, the consumption of drugs was a mutually enjoyable pastime among friends. Smoking marijuana was an occasional activity among friends rather than the foundation of their friendship. For these respondents, the consumption of drugs may strengthen friendships but not create them.

All respondents interviewed had experienced interactions with police. While individual experiences varied, they all expressed a desire to avoid the police and employed avoidance tactics. Outdoor users adopted strategies to avoid police detection when purchasing, selling or consuming drugs. This often meant relying on other users as part of a group or consuming drugs in hiding in isolated places such as bushes or alleyways. Indoor users also sought to avoid police. Being indoors gave them a safe space and as a result they did not adopt the same strategies as outdoor users.

Police can have a direct impact on the social relationships and friendships formed by street involved users. In certain instances, users rely on friendship groups to avoid police interactions and choose friends they can trust not to inform police regarding their drug use.

\section{Contributions of this study}

This study examined the lived experiences of street involved drug users and examined how they account for and understand their own drug consumption. It challenged the commonly held notion that street involved people consume drugs differently than non-street involved 
people. By understanding this misconception, it is possible to appreciate current public policies affecting this population and why street involved people are policed differently. Exploring society's misconceptions allows us to create better public policy and improve how police interact with marginalized populations.

The stigmatization of a "junkie" within street involved populations is the same as within other populations. Consumption habits of respondents were often formed to avoid the subjective position of "junkie". Understanding that street involved users avoid the "junkie" label allows for better public policy and services. Services to help street involved drug users, or street involved and homeless populations in general, should avoid being perceived for "junkies". Failing to do so may result in a less effective program or service that fewer individuals use. Decriminalization or legalization may not fully remove the social stigma surrounding street involved drug consumption and street involved populations, however, a move in this direction would mean that street involved drug users are no longer inherently criminal in the eyes of the law. The law would no longer be contributing to the stigmatization of street involved populations. This may also change the relationship between police and street involved populations, and how street involved populations perceive their relationship and interactions with police.

\section{Areas of further study}

Future research that builds on this study could be conducted at other shelters in Ottawa and in other cities to see if results were replicated in different locations. Researchers looking to build upon this work could interview the police to examine how police view street involved drug users and their attitudes towards street level drug use. This would also allow researchers to understand their perceptions of application of drug laws. 
Researchers may also wish to interview non-street involved drug users and compare their consumption habits with street involved users, examining if and how they differentiate between acceptable and unacceptable drug use and if they actively work to avoid the "junkie" label. Interactions with police could be included to compare with street involved users.

Further research building on this study could look at groups that were not part of this study. This may include women, people of colour, First Nations, LGBTQ persons, youth and those currently sleeping outdoors. Researchers could see if the findings of this study are applicable to other identifiable groups. These groups may all have different experiences with police and different social relationships.

Additional research may examine specific categories of drug users. This study looked at street involved users of both soft and hard drugs, as well as those who did and did not use needles. Future research could look specifically at individuals who only use soft drugs, only hard drugs or those that frequently use needles. A breakdown of users into smaller subsections may allow for a more detailed analysis.

A final area of inquiry could look at policy makers and examine how they view street involved people when creating laws and policies. Research could examine whether the wellbeing of street involved people factors into policy maker's decisions. It could examine how policy makers view street involved people more generally. Do they see them as one homogenous group or do they make distinctions? This type of research could allow for a more nuanced understanding of the internal logic policy makers use when creating laws and policies that impact street involved people either intentionally or not.

With the pending legalization of marijuana in Canada researchers could re-examine the relationship after marijuana becomes legal. The criminalization creates an inherently adversarial 
relationship between users and the police and supports "junkie" stigmatization. While users do not necessarily dislike police, they avoid them due to the illegal nature of drug use. Once marijuana is legalized the relationship between users of soft drugs, namely marijuana, and police could be different. Researchers could examine if this relationship changes and how this change impacts street involved users.

\section{Limitations of study}

This study considered street involved adult male drug users. No women were interviewed meaning that this study cannot account for the experience of female street involved drug users. Furthermore, the study did not examine the role that gender plays in the experiences that street involved users have both with police and other users.

This study focussed on users who were over 18 so experiences of youth users were not included. Previous studies on youth drug use by Karen Foster and Dale Spencer had similar findings as this study pertaining to users' ability to define acceptable and unacceptable drug use. The impact of police and the interaction with police as it pertains to youth drug users is still unclear and this study did not examine this.

All those interviewed were white, no people of colour or First Nations individuals volunteered to participate. There was no intention to limit research participants to white respondents but that was who volunteered. The locations at which interviews were conducted has a predominantly white clientele. As a result, this study did not examine the impact race may have on interactions with police and with fellow users. The experiences of racially marginalized drug users may be substantially different than the experiences of white drugs users, especially as it pertains to their interactions with police. 
All respondents were currently sleeping indoors at the shelter, though some previously slept outdoors. As a result, the most marginalized group of street involved users may have been missed. This group may have a different experience with police, and different social relations than those interviewed for this study. The experiences of LGBTQ individuals were not expressly considered. They may have different experiences and interactions with police and this was never looked at in this study.

Another limitation may be that all respondents understand their drug consumption within the dominant drugs and drug use discourse. As such, many of the dominant narratives about drug consumption are evident. A sample of respondents not impacted by the dominant discourse may present a different understanding of drugs and drug consumption. A sizeable sample group may be hard to find; however, it would show how external societal factors impact the subjectivity of street involved drug users.

\section{Reflections}

Before the study, I thought that street involved drug users were a homogenous group and was unaware of how they define their drug consumption and how they perceive a "junkie".

Through the study I grew to understand the impact that police have on the lives of street involved and homeless men. Some respondents spoke positively of police while others reported negative experiences. They all avoided police whenever possible and routinizing various avoidance strategies.

I have gained a new appreciation for the skills required to be a good interviewer. Knowing when to probe further and to ensure I did not miss any of the fine details respondents 
spoke of was difficult at first. I was both pleased and slightly surprised with respondents' candidness.

The process of writing a thesis was long and at times difficult but also thoroughly rewarding. I hope this study can make meaningful contributions to both academics and the street involved men who were generous enough to participate.

Results of the study were based in the current policy context which will undergo substantial change due to increased legalization of marijuana and the safe injection facility coming to Ottawa. This may change how some users interact with police as well as where drugs are consumed. I am curious to see how this impacts the lives of street involved drug users. 


\section{$\underline{\text { Appendix }}$}

\section{$\underline{\text { Interview Guide }}$}

\section{Preamble}

The following questions are regarding demographic details. The purpose of these questions is to better understand your history in the city and better understand your experiences living in Ottawa. All answers given will be kept confidential and your identity will be protected through assigning pseudonym to your interview [explain if necessary].

\section{Demographic question}

1. How old are you?

2. Were you born in Ottawa? If not when did you move here?

3. Have you lived in Ottawa all your life? If not where else have you lived?

4. What area of the city do you currently live in?

5. When did you first start using drugs?

6. What's the longest you've gone without using drugs?

\section{Life style and identity questions}

1. Where do spend most of your time?

2. What do you do as part of your daily routine?

3. How would you describe your current living situation?

4. How do you view yourself?

5. How do you think others view you and why?

6. Have you changed your behaviour at all based on how you believe other people view you?

7. What do you do in your spare time?

8. Which drop in centers do you use? Why do you choose to come to this particular one?

\section{Drug use questions}

1. When did you first use drugs?

2. How often do you use drugs?

3. What types of drugs do you most often use?

4. Are there any drugs you won't use and why not?

5. What are you comfortable sharing with me, about the way you get and use drugs?

6. Who do you do drugs with?

7. How did you meet the people you use drugs with? 
8. How would you describe the people you do drugs with?

9. What type of relationship do you have with the people you do drugs with?

10. Why do you do drugs with these particular individuals?

11.How does getting and using drugs effect your day to day routine?

\section{Interaction with police question}

1. Do the police have an impact on how you get or use drugs? If so, can you tell me about it?

2. How do the police treat you?

3. Are there certain places in the city that the police treat you different?

4. Which places are these?

5. What do you think the police think of you and why?

6. What strategies do you use to avoid police when obtaining and using drugs?

7. Have the police ever caught you doing or buying drugs and has this changed how you buy and use drugs at all? 


\section{$\underline{\text { Bibliography }}$}

Alvesson Mats, and Kaj Sköldberg, "Reflexive Methodology: New Vistas for Qualitative Research", (Thousand Oaks, California: SAGE, 2009).

“Am I an Addict?" Narcotics Anonymous World Services, Inc, 1988. Available online at $<$ https://www.na.org/admin/include/spaw2/uploads/pdf/litfiles/us_english/IP/EN3107.pdf>

Barnes, Mario. "Black women's stories and the criminal law: restating the power of narrative", U.C. Davis law review 39:3 2006. Becker, Howard. Outsider, (2008) New York, NY: Simon and Schuster.

Belackova, Vendula and Christian Alexander Vaccaro, ““”A Friend With Weed Is a Friend Indeed": Understanding the Relationship Between Friendship Identity and Market Relations Among Marijuana Users", Journal of Drug Issues 43:3 2013. Besley, Tina, Michael A. Peters, Subjectivity \& Truth: Foucault, Education, and the Culture of Self, (2007) New York, NY: Peter Lang Publishing.

"Best Practices Methadone Maintenance Treatment", Health Canada 2002.

Blanchfield, Mike. "Legal pot will run afoul of global treaties, PM warned", The Canadian Press, January 5, 2016. Available online

$<$ http://www.theglobeandmail.com/news/politics/legalizing-pot-in-canada-will-run-afoulof-global-treaties-trudeau-warned/article28027192/>

Bogazianos, Dimitri A. 5 Grams Crack Cocaine, Rap Music, and the War on Drugs. (2012) New York: New York University Press 2012.

Boyd, Susan C. Hooked: Drug War Films in Britain, Canada, and the United States, (Toronto: University of Toronto Press, 2009).

Boyd, Susan C. and Connie Carter. Killer Weed: Marijuana Grow Ops, Media, and Justice, (Toronto: University of Toronto Press, 2014).

Bray, Robert M., Mary Ellen Marsden, Drug Use in Metropolitan America, (1999) Thousand Oaks, California: SAGE.

Alan Bryman, Social Research Methods, (Oxford, UK: Oxford University Press, 2015).

Burgess, Ann Wolbert, Cheryl Regehr, Albert R. Roberts. Victimology: Theories and Applications, (2011) Sudbury, MA: Jones \& Bartlett Publishers.

Butcher, Melissa, "Cultures of Commuting: The Mobile Negotiation of Space and Subjectivity on Delhi’s Metro", Motilities, 6:2 2011. Butler, Martha and Karin Phillips. "Legislative Summary of Bill C-2: An Act to amend the Controlled Drugs and Substances Act", Legal and Social Affairs Division 4 November 2013. 
Campbell, Robert A. "Profit Was Just a Circumstance": The Evolution of Government Liquor Control in British Columbia 1920-1988" in Drink in Canada: Historical Essays, (Montreal: McGill-Queen's Press - MQUP, 1993).

Canada (Attorney General) v. PHS Community Services Society, 2011 SCC 44, [2011] 3 S.C.R. 134.

Carstairs, Catherine. Jailed for Possession: Illegal Drug Use, Regulation, and Power in Canada, 1920-1961, (Toronto: University of Toronto Press, 2006).

Clover, Darlene. "Successes and challenges of feminist arts-based participatory methodologies with homeless/street-involved women in Victoria", Qualitative Social Work 9:1 2015.Cossentino, Jacqueline, "Ritualizing Expertise: A Non-Montessorian View of the Montessori Method", American Journal of Education, 111:2, 2005

Cortazzi, Martin. Narrative Analysis, (Abingdon, Oxon: Routledge, 2014).

Cresswell, Tim, "Moral Geographies" in Cultural Geography: A Critical Dictionary of Key Ideas, (New York: I.B.Tauris, 2007).

Csiernik, Rick and Robin Koop-Watson. "Many Paths to Prohibition: Drug Policy in Canada", in Responding to the Oppression of Addiction: Canadian Social Work Perspectives, (Toronto: Canadian Scholars Press, 2010).

de Certeau, Michel, The Practice of Everyday Life, Volume 1. (University of California Press. Los Angeles, California. 2011).

Desroches, Frederick John. The Crime that Pays: Drug Trafficking and Organized Crime in Canada, (Toronto: Canadian Scholars' Press, 2005).

Donnelly, Taylor. “'Just One Step Away': The Mad Other on the Contemporary Stage”, Otherness: Essays and Studies 2:2 2012.

Donohew, Lewis, Howard E. Sypher, William J. Bukoski, Persuasive Communication and Drug Abuse Prevention, (1991) Hillsdale, NJ: Lawrence Erlbaum Associates Inc Publishers.

"Drug Facts: Understanding Drug Abuse and Addiction" National Institute of Drug Abuse, November 2012. Available online at $<$ http://www.drugabuse.gov/publications/drugfacts/understanding-drug-abuse-addiction>

Elliott, Richard Ian Malkin, and Jennifer Gold. "Establishing Safe Injection Facilities in Canada: Legal and Ethical Issues", Canadian HIV AIDS Legal Network 2002.

Erickson, Patricia G. and David L Haans. "Drug War, Canadian Style", in Drug War American Style: The Internationalization of Failed Policy and its Alternatives, (New York: Garland Publishing, 2001). 
Evans. Douglas, Gerard Hastings. Public Health Branding: Applying Marketing for Social Change, (2008) Oxford, United Kingdom: Oxford University Press.

Friedman, Samuel R. Don C. Des Jarlais, Jo L. Sotheran. "AIDS Health Education for Intravenous Drug Users", Health Education Quarterly Winter 1986.

Foster, Karen and Dale Spencer. “'It's just a social thing': Drug use, friendship and borderwork among marginalized young people”, International Journal of Drug Policy 242013.

Galabuzi, Grace-Edward, Canada's Economic Apartheid: The Social Exclusion of Racialized Groups in the New Century, (Toronto, ON: Canadian Scholars' Press, 2006).

Gibbs Graham R. Analysing Qualitative Data, (Thousand Oak, CA: SAGE, 2008).

Giffen, P.J, Shirley Jane Endicott, and Sylvia Boorman. Panic and Indifference: The Politics of Canada's Drug Laws in Social Origins of Narcotic Prohibition (Canadian Centre on Substance Abuse 1991).

Gleghorn, Alice A., Rani Marx , Eric Vittinghoff, and Mitchell H. Katz "Association between drug use patterns and HIV risks among homeless, runaway, and street youth in Northern California”, Drug and Alcohol Dependence 51:3 1998.

Goodman, Leo A. “COMMENT: ON RESPONDENT-DRIVEN SAMPLING AND SNOWBALL SAMPLING IN HARD-TO-REACH POPULATIONS AND SNOWBALL SAMPLING NOT IN HARD-TO-REACH POPULATIONS", Sociological Methodology 41:1 2011.

Grace-Edward Galabuz, Canada's Economic Apartheid: The Social Exclusion of Racialized Groups in the New Century, (Toronto, ON: Canadian Scholars' Press, 2006).

Grayson, Kyle. Chasing Dragons: Security, Identity, and Illicit Drugs in Canada, (Toronto: University of Toronto Press 2008).

Harris, Othello and R. Robin Miller. Impacts of Incarceration on the African American Family, (New Brunswick, NJ: Transaction Publishers, 2003).

Hebdige, Dick. Subculture, (2003) New York, NY: Routledge.

Jacobs, Bruce A. Dealing Crack: The Social World of Streetcorner Selling, (1999) Boston, MA: North Eastern University Press.

Kandel, Denise, and Mark Davies, "FRIENDSHIP NETWORKS, INTIMACY, AND ILLICIT DRUG USE IN YOUNG ADULTHOOD: A COMPARISON OF TWO COMPETING THEORIES", Criminology 29:3 1991. Keene, Jan. "Understanding Drug Misuse: Models of Care and Control”, (2010) New York, New York: Palgrave Macmillan. 
Kerr, Thomas, Will Small, Evan Wood . "The public health and social impacts of drug market enforcement: A review of the evidence", International Journal of Drug Policy 162005.

Lenton, Simon and Eric Single. "The definition of harm reduction", Drug and Alcohol Review 171998.

Lyman, Michael D. Drugs in Society: Causes, Concepts and Control, (2010) Burlington, MA: Anderson Publishing.

Lynch, Mona, Marisa Omori, Aaron Roussell, and Matthew Valasik, "Policing the 'progressive' city: The racialized geography of drug law enforcement" Theoretical Criminology $17: 3$.

Maddan, Sean. The Labeling of Sex Offenders: The Unintended Consequences of the Best Intentioned Public Policies, (2008) Lanham, Maryland: University Press of America.

Malleck, Dan. "When Good Drugs Go Bad: Opium, Medicine, and the Origins of Canada's Drug Laws", (Vancouver: UBC Press, 2015).

Mallea, Paula. The War on Drugs: A Failed Experiment, (Toronto: Dundurn, 2014).

Markert, John, Hooked in Film: Substance Abuse on the Big Screen, (2013) Lanham, Maryland: Scarecrow Press.

Marlatt, G. Alan. "Harm reduction: Come as you are", Addictive Behaviours 21:6 1996.

Marquis, Greg. "From Beverage to Drug: Alcohol and Other Drugs in 1960s and 1970s Canada" in The Real Dope: Social, Legal, and Historical Perspectives on the Regulation of Drugs in Canada, (Toronto: University of Toronto Press, 2011).

McLaren, John. Race and the Criminal Justice System in British Columbia, 1892-1920, in Essays in the History of Canadian Law: In honour of R.C.B. Risk ed. (Toronto: University of Toronto Press, 1999).

Mooney, Linda A., David Knox, and Caroline Schacht. Understanding Social Problems. (Belmont, CA: Cengage Learning, 2010).

Montigny, Edgar-André. "The Real Dope: Social, Legal, and Historical Perspectives on the Regulation of Drugs in Canada", (Toronto: University of Toronto Press, 2011).

Murphy, Emily. Black Candle, Part 2, Chapters 17-25. Available on Freeworldnews.com. $<$ http://www.freeworldnews.com/p2 17to25.html\#Marahuana-A New_Menace> 
Nathanson, Constance A. Disease Prevention as Social Change: The State, Society, and Public Health in the United States, France, Great Britain, and Canada. (New York: Russell Sage Foundation, 2007).

Marshall, Brandon D.L., Thomas Kerr, Jean A. Shoveller, Thomas L. Patterson, Jane A. Buxton, and Evan Wood, "Homelessness and unstable housing associated with an increased risk of HIV and STI transmission among street-involved youth", Health \& Place 15:3 2009.

McCormick, Tyler H., Ran He, Eric Kolaczyk, and Tian Zheng "Surveying Hard-toReach Groups Through Sampled Respondents in a Social Network A Comparison of Two Survey Strategies", Statistics in Bioscience 4:1 2012.

McKeganey, Neil. A-Z of Substance Misuse and Drug Addiction, (2014) New York , NY: Palgrave Macmillan.

Mitchell, Don, "The annihilation of space by law: the roots and implications of antihomeless laws in the United States", Antipode 39:3 1997.

"Needle Exchange Programs (NEPs) FAQs", Canadian Centre on Substance Abuse. At page 3. Available online at $<$ http://www.ccsa.ca/Resource\%20Library/ccsa-010055-2004.pdf $>$

Nestler, Eric J., Bruce T. Hope, and Katherine L. Widnell, "Drug addiction: A model for the molecular basis of neural plasticity", Neuron 11:6 1993.

Niland, Patricia, Antonia C. Lyons, Ian Goodwin, Fiona Hutton. ““"Everyone can loosen up and get a bit of a buzz on": Young adults, alcohol and friendship practices", International Journal of Drug Policy 24:6 2013.

Nutt, David J. Leslie A King, Lawrence D Phillips. "Drug harms in the UK: a multicriteria decision analysis" (2010) 376 The Lancet 1558.

Opium Act 1908 - Chapter 12 Available online at $<$ http://www.parl.gc.ca/Content/SEN/Committee/371/ille/rep/repfinalvol2-e.htm\#>

Oxoby, Marc. The 1990s, (2003) Westport, CT: Greenwood Publishing Group.

Paulus, Ingeborg and Robert Halliday. "Rehabilitation and the Narcotic Addict Results of a Comparative Methadone Withdrawal Program", Canadian Medical Association Journal 96:11 1967.

Peachey, J. E. and T. Franklin. "Methadone Treatment of Opiate Dependence in Canada", British Journal of Addiction 80:3 1985.

Pilkington, Hilary. "In good company: risk, security and choice in young people's drug decisions", The Sociological Review 55:2 2007. 
Phillips, Joshua D., Homeless: Narratives from the Streets, (2015) North Carolina: McFarland, 2015.

http://www.rehabs.com/explore/faces-of-addiction/

Riley, Diane. "The Harm Reduction Model: Pragmatic Approaches to Drug Use from the Area between Intolerance and Neglect", Canadian Centre on Substance Abuse 1993. Available Online at $<$ http://epe.lac-bac.gc.ca/100/200/300/ccsa-cclat/harm_reduction_modele/harmred.htm>

Robertson, Leslie, "Taming Space: Drug use, HIV, and homemaking in Downtown Eastside Vancouver”, Gender, Place \& Culture, 14:5 2007.

Robinson, Matthew B., Renee G. Scherlen, Lies, Damned Lies, and Drug War Statistics, Second Edition: A Critical Analysis of Claims Made by the Office of National Drug Control Policy, (2014) Albany, NY: University of New York Press.

Rose, Nikolas. Inventing Our Selves: Psychology, Power, and Personhood, (1998) New York, NY: Cambridge University Press.

Sheikh, Sana and Meghan E. McNamara. "Insights from Self-Blame and Victim Blaming”, Psychological Inquiry 25:2 2014.

Shiner, Larry. "Sacred Space, Profane Space, Human Space", Journal of the American Academy of Religion 40:4 1972.

Shaver, Kelly G., Principles of Social Psychology: Third Edition, (New York, NY: Psychology Press, 2015)

Shlay, Anne B. and Peter H. Rossi, "Social Science Research and Contemporary Studies of Homelessness", Annual Review of Sociology 18, 1992.

Sidanius, Jim, and Felicia Pratto. Social Dominance: An Intergroup Theory of Social Hierarchy and Oppression, (2001) Cambridge, UK: Cambridge University Press.

Singer, Merrill, J Bryan Page, Social Value of Drug Addicts: Uses of the Useless, (2014) Walnut Creek, CA: Left Coast Press.

Solomon, Robert R. and Melvyn Green. "The First Century: The History of Non-Medical Opiate Use and Control Policies in Canada 1870-1970", in Crime and Deviance in Canada: Historical Perspectives, (Toronto: Canadian Scholars' Press, 2005). 
Spooner, Catherine. "Impacts of stigma on HIV risk for women who inject drugs in Java: A qualitative study”, International Journal of Drug Policy 26:12 2015.

Statutes of Canada 1908, c. 50

Forrest Stuart, 'From 'Rabble Management' to 'Recovery Management': Policing Homelessness in Marginal Urban Space”, Urban Studies 51:9 2014.

"Substance Abuse and Homelessness", National Coalition for the Homeless, July 2009

Taylor, K.W. "Racism in Canadian immigration policy," Canadian Ethnic Studies 23:1 (1991).

Tempalski, Barbara, and Hilary McQuie, "Drugscapes and the role of place and space in injection drug use-related HIV risk environments", International Journal of Drug Policy 4:13 2009.

“Thirty Years of America's Drug War a Chronology", Frontline. Available online < http:/www.pbs.org/wgbh/pages/frontline/shows/drugs/cron/>

Ti, Lianping, Evan Wood, Kate Shannon, Cindy Feng, Thomas Kerr. "Police confrontations among street-involved youth in A Canadian setting", International Journal of Drug Policy 24:1 2013

Trumbetta, Susan, Kim T. Mueser, Ernest Quimby, Richard Bebout, Gregory B. Teague. "Social networks and clinical outcomes of dually diagnosed homeless persons", Behaviour Therapy 301999.

Vancouver Costal Health Supervised Injection Site. "Services" Available Online. $<$ http://supervisedinjection.vch.ca/services/services $>$.

"Vancouver's Insite drug injection clinic will stay open Top court rules on clinic's exemption from federal drug laws", $C B C$ News, September 30, 2011. Available online at $<$ http://www.cbc.ca/news/canada/british-columbia/vancouver-s-insite-drug-injection-clinic-willstay-open-1.1005044>

Walby, Kevin, and Randy Lippert, "Spatial Regulation, Dispersal, and the Aesthetics of the City: Conservation Officer Policing of Homeless People in Ottawa, Canada", Antipode 44:3 2011.

Walker, James W. St. G. "“Race," Rights and the Law in the Supreme Court of Canada: Historical Case Studies", (Canada: The Osgoode Society for Canadian Legal History and Wilfred Laurier University Press, 1997).

Way, Lori Beth, and Ryan Patten, Hunting For "Dirtbags”, (Boston: Northeastern University Press, 2013). 
Weitzer, Ronald. "Racialized policing: Residents' perceptions in three neighborhoods", Law \& Society Review 31:1 2000

Wright, Nat. Drug Users With Special Needs Drug Use and Homelessness in "are of Drug Users in General Practice: A Harm Reduction Approach", (2004) United Kingdom: Radcliffe Publishing. 